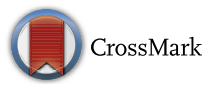

Cite as

Nano-Micro Lett.

(2019) 11:5

Received: 29 October 2018

Accepted: 10 December 2018

Published online: 10 January 2019

(C) The Author(s) 2019

\section{Enhanced Roles of Carbon Architectures in High-Performance Lithium-Ion Batteries}

\author{
Lu Wang ${ }^{1}$, Junwei Han ${ }^{1}$, Debin Kong ${ }^{2}$, Ying Tao ${ }^{1}$, Quan-Hong Yang ${ }^{\circledR}$ \\ Lu Wang and Junwei Han have contributed equally to this work. \\ $\triangle$ Debin Kong, kongdb@nanoctr.cn; Quan-Hong Yang, qhyangcn@tju.edu.cn \\ 1 Nanoyang Group, State Key Laboratory of Chemical Engineering, School of Chemical Engineering \\ and Technology, Collaborative Innovation Center of Chemical Science and Engineering (Tianjin), Tianjin \\ University, Tianjin 300072, People's Republic of China \\ 2 CAS Key Laboratory of Nanosystem and Hierarchical Fabrication, CAS Center for Excellence \\ in Nanoscience, National Center for Nanoscience and Technology, Beijing 100190, \\ People's Republic of China
}

\title{
HIGHLIGHTS
}

- Assembly strategies that reinforce the roles of carbon architectures as active materials, electrochemical reaction frameworks, and current collectors in high-energy and high-power lithium-ion batteries are summarized.

- To enhance structural stability and volumetric performance, the rational design of carbon architectures for high-capacity noncarbons in terms of the interface, network skeleton, void space, and densification, is discussed in detail.

- Designing carbon cages that protect the electroactive noncarbon is highlighted as a promising strategy that solves the challenges associated with future high-capacity noncarbon anode construction.

ABSTRACT Lithium-ion batteries (LIBs), which are high-energydensity and low-safety-risk secondary batteries, are underpinned to the rise in electrochemical energy storage devices that satisfy the urgent demands of the global energy storage market. With the aim of achieving high energy density and fast-charging performance, the exploitation of simple and low-cost approaches for the production of high capacity, high density, high mass loading, and kinetically ion-accessible electrodes that maximize charge storage and transport in LIBs, is a critical need. Toward the construction of high-performance electrodes, carbons are promisingly used in the enhanced roles of active materials, electrochemical reaction frameworks for high-capacity noncarbons, and lightweight current collectors. Here, we review recent advances in the carbon engineering of electrodes for excellent electrochemical performance and

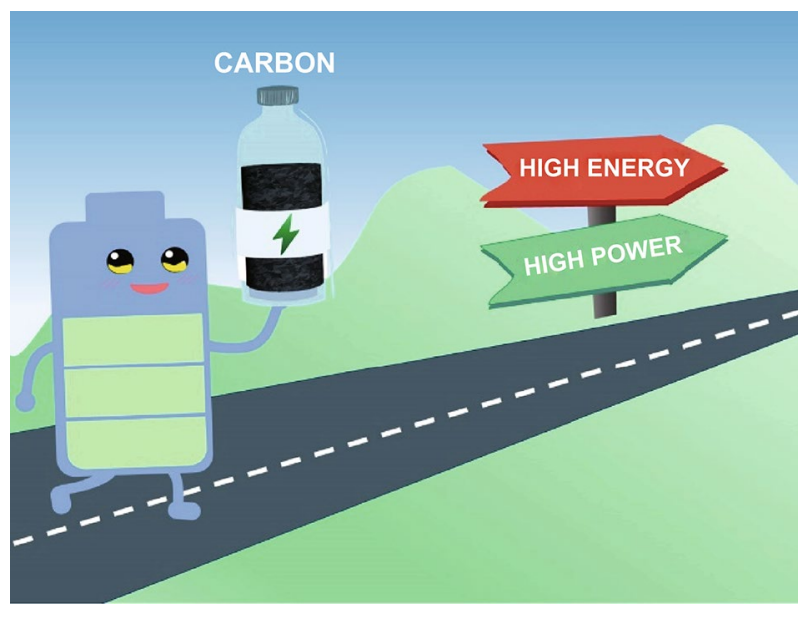
structural stability, which is enabled by assembled carbon architectures that guarantee sufficient charge delivery and volume fluctuation buffering inside the electrode during cycling. Some specific feasible assembly methods, synergism between structural design components of carbon assemblies, and electrochemical performance enhancement are highlighted. The precise design of carbon cages by the assembly of graphene units is potentially useful for the controlled preparation of high-capacity carbon-caged noncarbon anodes with volumetric capacities over $2100 \mathrm{mAh} \mathrm{cm}{ }^{-3}$. Finally, insights are given on the prospects 
and challenges for designing carbon architectures for practical LIBs that simultaneously provide high energy densities (both gravimetric and volumetric) and high rate performance.

KEYWORDS Lithium-ion battery; Carbon architecture; Energy density; Power density; Assembly

\section{Introduction}

Developing rechargeable electrochemical energy storage (EES) devices represents one of the most promising approaches to achieving high-performance energy storage, since they can provide large-scale and smart-grid energy storage with high levels of efficiency [1-5]. Over the past two decades, lithium-ion batteries (LIBs) have played key roles as EES devices in electronics applications, electrical vehicles, and large-grid energy systems due to their high energy densities and low safety risks [6-9]. Efforts have been made to engineer current graphitic anodes and transition metal oxide cathodes with enhanced ion diffusion and electrical conductivity for high-energy and highpower LIBs. Nevertheless, the further development of LIBs is largely constrained by the low theoretical capacities (100-350 $\mathrm{mAh} \mathrm{g}^{-1}$ ) of graphitic anodes and metal oxide cathodes based on the intercalation mechanism [10]. To further improve the energy densities of LIBs, noncarbon anodes that operate beyond the intercalation mechanism have emerged as promising alternatives for conventional graphitic anodes due to their higher theoretical specific capacities (1000-4000 mAh g ${ }^{-1}$ ). However, high-capacity noncarbon anodes suffer from drastic volume changes during cycling, which largely block their structural stabilities and induce repetitive electrolyte decomposition, leading to low Coulombic efficiency and rapid capacity fading. Even worse, a high-density and high-mass-loaded electrode that offers high energy density usually suffers from poor rate performance and structural failure owing to the large tortuosity associated with charge-carrier transport and accumulated volume expansion stress $[11,12]$. Therefore, to improve its energy density and further ensure its high-power capability and long cycle life, the electrode should be well designed to accommodate more charge, improve charge transport, and further enhance the structural stability of the electrode in terms of its density and thickness.

To improve energy and power densities, carbons have been widely used in LIBs, including, but not limited to, their use as active materials, conductive additives, and electrochemical reaction frameworks in electrodes. Graphite, as the-state-of-the-art anode material, was the final finishing touch for the commercialization of LIBs in 1991 [13]. Carbons are also promisingly introduced in high-capacity noncarbon active materials to buffer volume fluctuations and improve electrical conductivity, in order to build better LIBs. Highly conductive $s p^{2}$-type carbons are used as effective conductive additives to improve the electron transport in low-conductivity transition metal compound cathodes. Notably, in advanced carbon-based electrode research, the development of carbon nanostructures has been demonstrated as an alternative approach to improving the electrochemical performance and extending the cycle lives of LIBs, on account of their unique structural features, such as high specific surface areas, large amounts of pores, and short ion- and electron-transport pathways for electroactive particles [14]. Unfortunately, issues associated with the low tap density, low Coulombic efficiency, and prolonged charge-transfer distance across the electrode have also accompanied the introduction of carbon nanomaterials in electrodes, which blocks the electrochemical performance of electrodes based on practical packing densities and thicknesses, thereby hindering the ability to achieve high energy and power densities in LIBs [15]. Hence, assembly strategies have been developed that realize synergies between primary carbon nanostructures and advanced carbon architectures in high-performance electrodes. Different dimensional carbon nanomaterials, including zero-dimensional (0D) nanoparticles [16], one-dimensional (1D) nanowires or nanorods [17, 18], and two-dimensional (2D) nanoflakes [19, 20], etc., as building blocks, have been used to construct rational carbon architectures through suitable assembly methods and controllable experimental conditions. The assembly of these carbon-based nanomaterials not only retains their intrinsic electrical and mechanical properties, but also generates new characteristics through the achievement of close connections between the noncarbon units, interpenetrated charge-transport networks, large electrochemical reaction surface areas, intact electrolyte blocking layers, and high packing densities. 
A number of recent reviews have summarized the critical roles of carbon materials, such as carbon nanotubes, graphene, and carbon composites, in EES devices [21-23]. Fang et al. offered a general and objective understanding of the roles of carbon nanotubes and graphene in regulating lithium storage process in electroactive materials [21]. Our group discussed the use of graphene as soft templates in the design of well-controlled carbon composites for enhanced electrochemical performance [22]. In this review, we focus on recent research highlights of assembly strategies that reinforce the roles of the carbon architecture toward achieving high-energy and high-power LIBs (Fig. 1). First, we briefly discuss assembly methods used for carbon-based nanomaterials that enable the controllable construction of various morphologies and internal structures. Then, assembly strategies used for the construction of carbon architectures with enhanced roles of active materials, electrochemical reaction frameworks, and current collectors, which solve specific issues in electrodes, including low electronic conductivities, poor ion diffusions, low densities, side reactions with electrolytes, and large volume changes, will be discussed in detail. Strategies for designing carbon architectures, such as interfacial modulation, network skeleton design, void space manipulation, and densification engineering, are highlighted. In particular, the significance of the carbon-cage design for noncarbon materials is demonstrated by superior volumetric lithium storage and stable electrode structures during cycling. Finally, a brief summary and some perspectives on the applications of carbon architectures in practical LIBs are offered.

\section{Assembly Methods for the Construction of Carbon Architectures}

The fabrication of carbon-based materials with rationally designed structures and properties that directly determine their potentials in EES applications is of crucial importance.

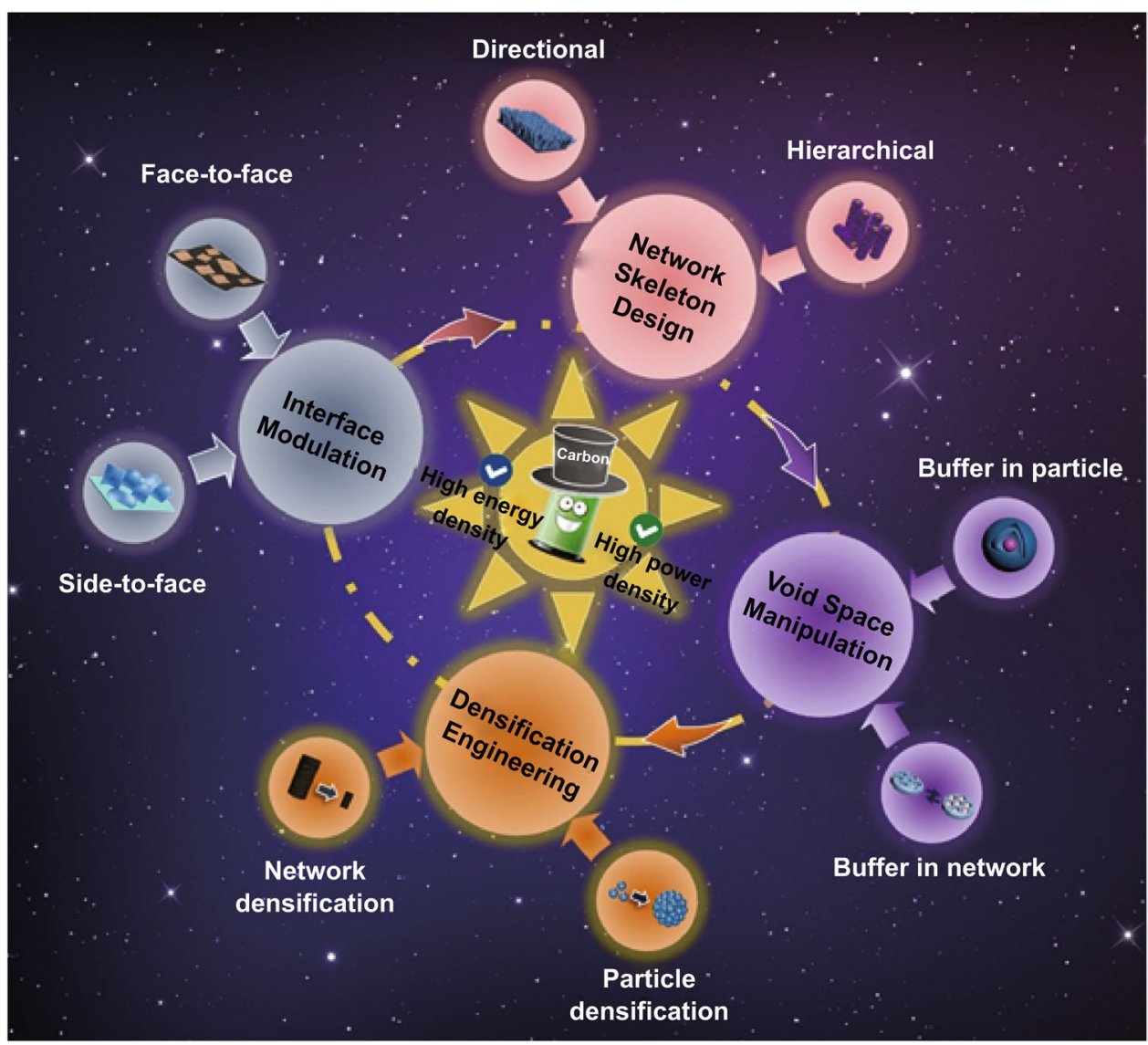

Fig. 1 Carbon-architecture assembly strategies for building high-energy and high-power LIBs 
Assembling carbon nanostructures into architectures not only retains the intrinsic properties of the carbon building blocks, but also facilitates good control over nanostructural arrangements and allows properties to be manipulated. Typical assembly methods, including electrospinning [24], chemical vapor deposition (CVD) [25], and self-assembly [26], have been widely used to synthesize carbon architectures. To further enhance controllability during carbon assembly, external influences, such as template assistance, vacuum force, electric- and magnetic field guidance, have been widely introduced and well developed in recent years. Hence, the following part mainly focuses on external force control during the carbon assembly process (Fig. 2).

Template-assisted assembly is one of the most frequently used strategies for fabricating hierarchically structured carbon-based materials. During the fabrication processes, the introduction of templates makes it easy to precisely control the sizes, shapes, structures, and properties of carbon-based nanomaterials for producing specially structured materials, such as nanofibers [27], nanotube arrays [28], core-shell structures [29], pomegranate-like structures [30], and 3D composite aerogels [31]. For example, with the assistance of porous alumina templates, coaxial manganese oxide/carbon nanotube $\left(\mathrm{MnO}_{2} / \mathrm{CNT}\right)$ arrays were fabricated by a combination of simple vacuum infiltration and CVD techniques, followed by alkali treatment to remove the templates [28]. Nevertheless, conventional templating methods may result in structural collapse during template-removal treatments, making it difficult to obtain more complicated structures (e.g., yolk-shelled and multi-shelled structures). Hence, a few advanced sacrificial template approaches, such as selftemplating [32-34], chemical oxidation [35], and thermal decomposition [36] methods, have been well developed. Typically, self-templated strategies can directly convert templates into hollow structures by controlled etching, outward diffusion, or heterogeneous contraction [37]. For instance, using a metal-organic framework (ZIF-67) as a self-template, $\mathrm{Xia}$ et al. synthesized a cobalt-phosphide-based $\left(\mathrm{Co}_{\mathrm{x}} \mathrm{P}-\mathrm{NC}\right)$ nanohybrid in situ [33], in which $\mathrm{Co}_{\mathrm{x}} \mathrm{P}$ nanoparticles were homogeneously embedded in a polyhedral porous nitrogen-doped carbon, which not only contributed to fast electron and lithium-ion transport, but also provided sufficient buffer space.

Force caused by pressure difference is another commonly used external driving force in material preparation, especially in the vacuum filtration method. The pressure difference between the two sides of the filter medium drives the deposition of the solid matter in the suspension onto the filter medium, which then forms a uniform film or paper-supported electrode, such as a cellulose-based paper anode [38],

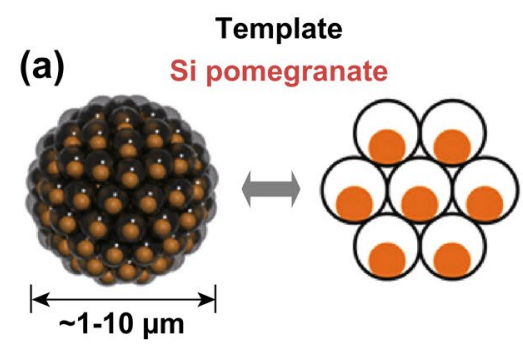

(b)
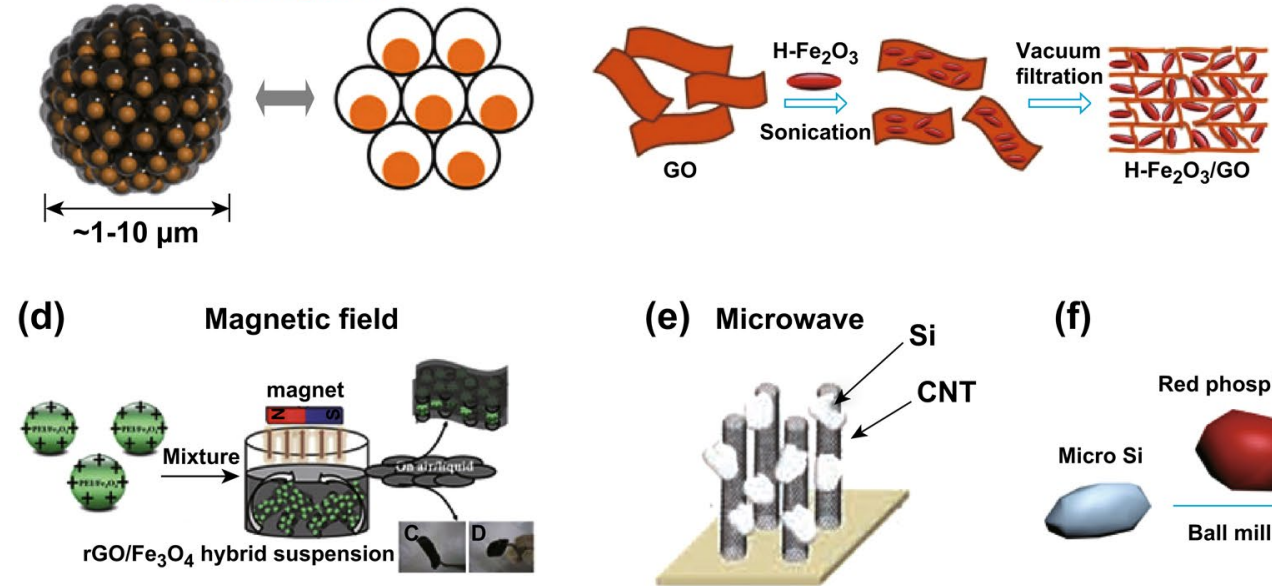

(e) Microwave

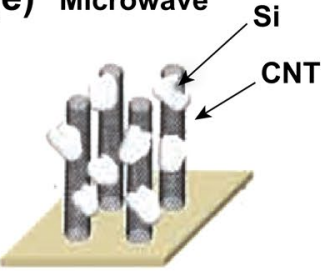

(f)

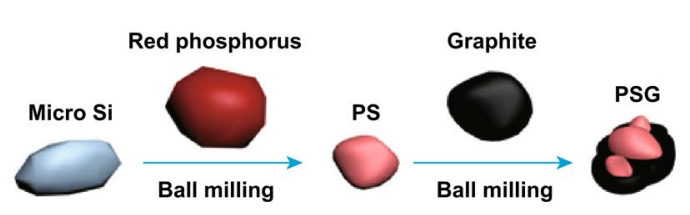

Fig. 2 Assembly methods with the assistance of external forces or fields. a Schematic of silicon pomegranates. Reprinted with permission from Ref. [30]. b Schematic of the fabrication process for $\mathrm{H}-\mathrm{Fe}_{3} \mathrm{O}_{4} / \mathrm{GS}$ hybrid films. Reprinted with permission from Ref. [39]. c Schematic of the gradient electrospinning and controlled pyrolysis method. Reprinted with permission from Ref. [45]. d Schematic of the synthesis $\mathrm{rGO}_{\mathrm{Fe}} \mathrm{O}_{4}$ hybrid paper. Reprinted with permission from Ref. [52]. e VA-CNTs/Si structure. Reprinted with permission from Ref. [56]. f Schematic of the fabrication processes for nanostructured P-doped Si/graphite composites. Reprinted with permission from Ref. [57] 
a hollow ferroferric oxide/graphene $\left(\mathrm{H}-\mathrm{Fe}_{3} \mathrm{O}_{4} / \mathrm{GS}\right)$ hybrid film [39], or a silicon/Cladophora nanocellulose/carbon nanotube hybrid film [40]. For example, using a simple filtration method, free-standing porous silicon nanowire (Si-NW) and graphene nanoribbon (GNR) papers were obtained, which possessed homogenous conductive pathways [41]. However, the difference in the filtration rates of various components in the suspension may result in an uneven distribution of components in the membrane. To solve the above problems, Gao et al. adopted a coupling technique involving spray deposition and vacuum filtration to produce a high-density ( $2.7 \mathrm{mg} \mathrm{cm}$ electrode $)$ and high-mass-loading $\left(\mathrm{LiFePO}_{4}\right.$ loading of $\left.5 \mathrm{mg} \mathrm{cm}^{-2}\right)$ lithium iron phosphate $\left(\mathrm{LiFePO}_{4}\right) /$ graphene nanoribbon/graphene (LFP/GNR/G) paper-like binder-free electrode [42]. Spray deposition technology ensures uniform component distribution in each droplet of the precursor slurry, which leads to good composite membrane uniformity.

The electrostatic-based technique is a typical low-cost and highly effective assembly method. Electrodeposition (ED) can be used as a simple and effective method to prepare ultrathin and highly ordered nanosheets. For instance, using an electrodeposition process, a three-dimensional (3D) porous self-supporting molybdenum sulfide/graphene $\left(\mathrm{MoS}_{\mathrm{X}} / \mathrm{G}\right)$ composite film was fabricated [43], in which the graphene nanosheets were anchored on nanogranuled $\mathrm{MoS}_{\mathrm{x}}$ particles. This film showed a well-developed porous structure and exceptional electrical performance. Electrophoretic deposition (EPD), another typical material-processing technique, entails a two-step process: the charged particles in a suspension are driven toward an electrode of opposite charge due to the influence of an electric field and are then deposited to form a compact film. Yang et al. developed a cobaltosic oxide/graphene $\left(\mathrm{Co}_{3} \mathrm{O}_{4} / \mathrm{G}\right)$ hybrid electrode by electrophoretic deposition [44]. Due to the excellent flexibility of graphene and the large number of voids in this sandwich-like structure, the structural integrity and unobstructed conductive network can be maintained during cycling. Electrospinning is another kind of widely used fiber production method that relies on electric force guidance. As a typical example, Niu et al. designed a gradient electrospinning method to produce mesoporous nanotubes and pea-like nanotubes that showed higher ionic and electronic conductivities and larger specific surface areas compared to traditional nanowires [45].

Magnetic field is a strong force capable of aligning ferromagnetic materials [46]. Magnetic-field-induced self-assembly is an effective strategy for the construction of micro-nano-ordered structures [47-49]. By controlling the magnetic field direction and the magnetic field line distribution, various ordered structural materials can be obtained simply and quickly $[50,51]$. For example, a magnetite reduced graphene oxide ( $\mathrm{rGO} / \mathrm{Fe}_{3} \mathrm{O}_{4}$ hybrid paper has been fabricated at the air/liquid interface, assisted by an external magnetic field, which achieved uniform size distribution and monodispersibility of $\mathrm{Fe}_{3} \mathrm{O}_{4}$ nanoparticles and avoided the agglomeration of graphene oxide sheets [52]. Additionally, through electroless deposition with a magnetic field and further annealing, Kawamori et al. prepared a nickel oxide $(\mathrm{NiO})$-covered nickel nanowire nonwoven cloth, which showed quite high cyclability as an electrode material, without binders, conductive additives, or current collectors [53].

Microwaves, another source of external force, also have a great effect on the carbon assembly processes. Normally, CVD methods can be used to synthesize conductive matrixes [54] or deposite other active materials [55] to form hybrid nanostructures. In particular, with the assistance of microwaves, vertically aligned structures can also be fabricated through CVD processes. For example, using a microwave plasma-enhanced CVD system and hydrogen fluoride (HF)-CVD technology, Gohier et al. synthesized vertically aligned CNTs decorated with Si-particle arrays (VA-CNTs/Si) [56]. This well-designed structure not only ensured the dispersion uniformity of the $\mathrm{Si}$ nanoparticles, but also provided short 3D transportation pathways for both lithium ions and electrons. Toward the optimization of material structures and organizations during preparation, the introduction of mechanical forces, such as in the typical high-energy ball-milling approach, is another common lowcost method. Huang et al. produced nanostructured phosphorus (P)-doped Si/graphite composites using a two-step ball-milling method, which exhibited fast transport for both lithium ions and electrons [57]. Ball milling is a cost-effective and easily scalable method, which makes it feasible for large-scale carbonbased material synthesis applications.

It is noted that, during the fabrication of carbon-noncarbon composites, additional complicated preparation processes for the carbon architectures are generally needed. Efforts have focused on one-step methods of preparing carbon-noncarbon hybrid architectures that not only simplify the preparation process to save time, but also result in high pack densities and closer contacts between the carbon and noncarbon materials [58]. In the one-step construction of 
carbon-noncarbon hybrid architectures, the assembly of the carbon buildings and the production of noncarbon components occur simultaneously; hence good mixing of the carbon and noncarbon precursors, and the subsequent coproduction of the carbon and noncarbon components, are necessary in the overall fabrication process.

\section{Enhanced Roles of Carbon Architectures in LIBs}

In a lithium-ion battery, the electrode side typically consists of an active material (anodic or cathodic material), a conductive carbon matrix, a binder, and a current collector, each of which impacts significantly on the whole battery performance. Carbon is a critical component of current LIBs, especially as active materials for lithium storage or conductive matrixes that accelerate electron transfer. Nevertheless, much effort needs to be dedicated to the assembly of the active carbon material to improve charge transport across thick electrodes. Furthermore, with the challenge of promoting practical applications of high-capacity noncarbon anode materials, the carbon should be well engineered to solve the emerging issues of structural and interfacial instabilities and side reactions with the electrolyte. In this part, a variety of advanced assembly strategies that reinforce the roles of the carbon architectures as active materials, electrochemical reaction frameworks, and current collectors in electrodes for high-performance and long-cycling LIBs, are fully discussed.

\subsection{High-Rate-Performance Carbonaceous Active Materials}

Carbon materials have been widely investigated as lithium-ion battery anode materials due to numerous merits, including their excellent electrical conductivities, superb chemical stabilities, high surface areas, light weights, and tunable porous structures. Significant research has focused on advanced and well-designed carbon-based materials, from the microscale to the nanoscale [59-61]. As the currently used anode material in commercial LIBs, graphite possesses excellent structural stability and reaction reversibility during lithium-ion intercalation/deintercalation processes. Nevertheless, further improving the fast-charging capabilities of thick graphite anodes remains challenging.
The directional assembly of graphite flakes to reduce tortuosity is a very effective way of improving the diffusion kinetics of lithium ions in graphite anodes. With the assistance of a magnetic field, Juliette et al. orientationally controlled anodic graphite flakes to achieve high mass loadings and excellent rate performance in LIBs (Fig. 3a-c) [62]. Coated with superparamagnetic nanoparticles, graphite flakes were engineered into a thick $(\sim 200 \mu \mathrm{m})$ and highly loaded $\left(\sim 10 \mathrm{mg} \mathrm{cm}^{-2}\right)$ electrode with an out-of-plane-aligned architecture under a rotating magnetic field. As a result, this highly load yet poorly tortuous graphite anode delivered a specific capacity $\left(\sim 200 \mathrm{mAh} \mathrm{g}^{-1}\right)$ that was three times higher than that of a conventional anode at a high charge/ discharge rate of $1 \mathrm{C}$ (Fig. 3d). Promisingly, magnetic field guidance during the assembly of electrode materials is a rapid method that is scalable to practical electrode engineering, and can form the basis for new fabrication processes that enable the fabrication of thick, inexpensive, and high-powerdensity electrodes.

The assembly of carbon building blocks into 3D carbon networks also plays a significant role in enhancing the rate performance of carbon anodes, especially for graphenederived structures [63]. Wang et al. fabricated a high density $\left(1.1 \mathrm{~g} \mathrm{~cm}^{-3}\right) \mathrm{N}$-doped holey-graphene monolith (NHGM) using a one-pot hydrothermal process with hydrogen peroxide $\left(\mathrm{H}_{2} \mathrm{O}_{2}\right)$ as an added etching agent [64]. Due to efficient diffusion channels for lithium ions across graphene planes, highly conductive pathways for electrons, and incremental edges on sheets that enhanced lithium-ion intercalation, the as-prepared NHGM delivered a high volumetric capacity above $800 \mathrm{mAh} \mathrm{cm}^{-3}$ at a high rate of $3.2 \mathrm{~mA} \mathrm{~cm}^{-2}$, and with a high mass loading of $2.75 \mathrm{mg} \mathrm{cm}^{-2}$. Inspired by branched structures in nature, a highly branched 3D N-doped graphitic (BNG) tubular foam was fabricated using template-assisted single-source $N, N$-dimethylformamide (DMF)-CVD technology [65]. Homogeneous N-doping in the branched 3D-BNG not only produced defects in both the flat and curved parts that contributed to increased capacity, but also enlarged the spacing distances in both the flat and curved parts $(\approx 0.40 \mathrm{~nm})$, leading to a better rate capability. Consequently, when acting as the anode material in a lithium-ion battery, the BNG foam showed remarkably superior capacity $\left(1049 \mathrm{mAh} \mathrm{g}^{-1}\right.$ at $\left.500 \mathrm{~mA} \mathrm{~g}^{-1}\right)$, excellent cycling performance $\left(725 \mathrm{mAh} \mathrm{g}^{-1}\right.$ even after 200 cycles at $1500 \mathrm{~mA} \mathrm{~g}^{-1}$ ), and enhanced rate performance ( $451 \mathrm{mAh} \mathrm{g}^{-1}$ at $2.09 \mathrm{C}$ ). 


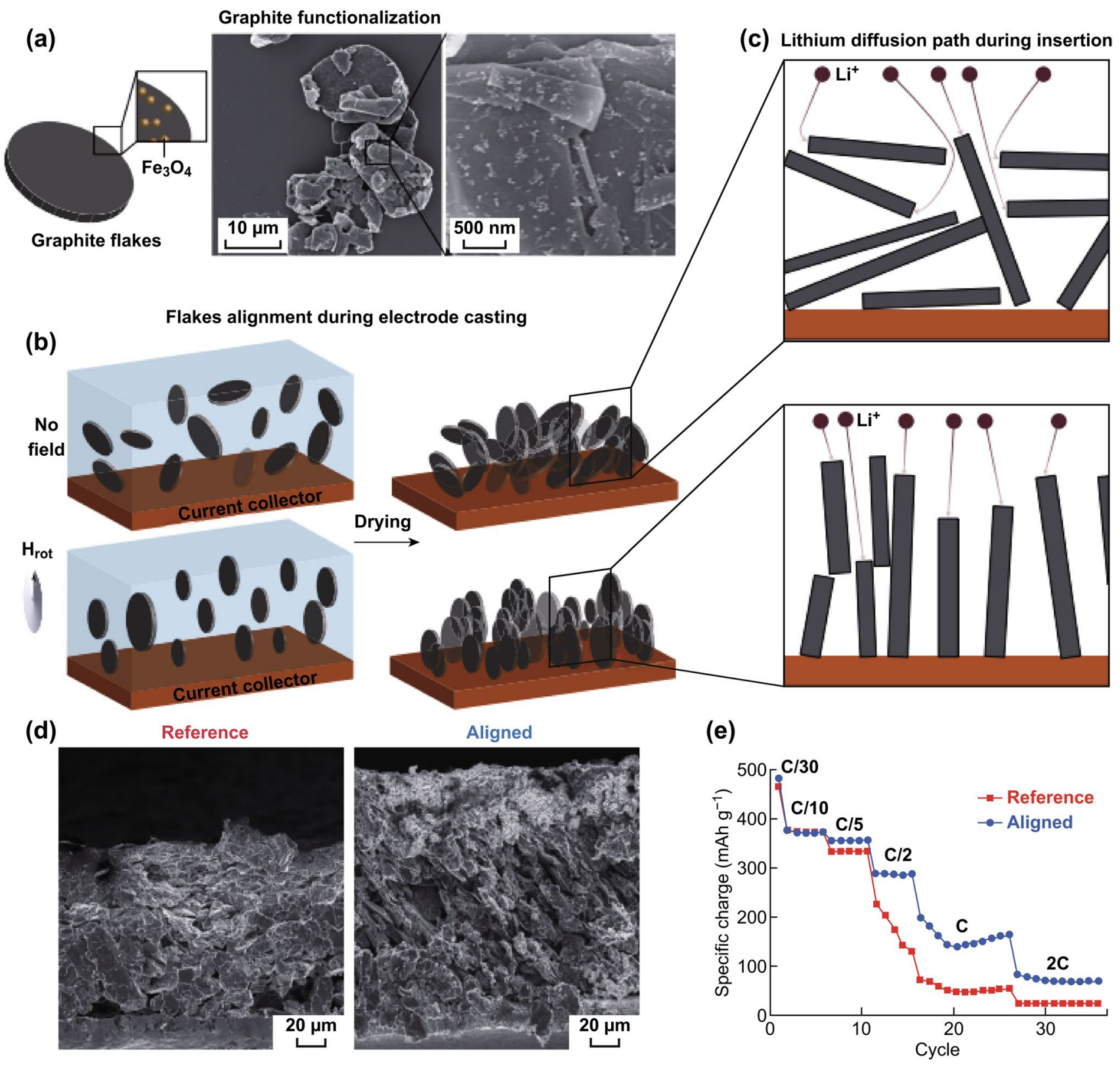

Fig. 3 a Sketch and SEM images of graphite flakes coated with $\mathrm{Fe}_{3} \mathrm{O}_{4}$ nanoparticles. b Graphite-electrode casting. c Sketch depicting lithium diffusion pathways in both electrode architectures. d Rate capability. Reprinted with permission from Ref. [62]

\subsection{High-Efficiency Carbon-Based Electrochemical Reaction Frameworks}

To further increase the energy densities of LIBs, many researchers have focused on high-capacity anode materials, including alloy-based anode materials (e.g., $\mathrm{Si}, \mathrm{Sn}$, and Ge) [66-68], metal oxides (e.g., $\mathrm{Co}_{3} \mathrm{O}_{4}, \mathrm{Fe}_{3} \mathrm{O}_{4}$, and $\mathrm{SnO}_{2}$ ) [69-72], and layered metal dichalcogenides $\left(\mathrm{MX}_{2}\right.$, e.g.,
$\mathrm{MoS}_{2}$ and $\mathrm{WS}_{2}$ ) [73, 74], to replace low-capacity graphitic anode materials. However, these active electrode materials with high specific capacities have low intrinsic electronic conductivities and suffer from drastic lithiation-induced volume expansions, which prevent their use in practical LIBs [75].

Carbons, used as second phases, are generally introduced into noncarbon materials to achieve promisingly high 
capacities and long-term cycling performance [76-78]. Furthermore, architectures constructed using carbon building blocks not only offer large surface areas to load noncarbon active particles, but also provide interconnected conductive networks, effective protective layers, and sufficient void spaces for noncarbons during cycling. As the supporting electrochemical matrix, the structural design of the carbon component significantly influences the electrochemical performance of the electrode. Thus, in the following section, we discuss the roles of carbon architectures in terms of interfacial optimization, network construction, and void space and densification designs, which are equally important for improving electronic and ionic conductivities, Coulombic efficiencies, packing densities, and the structural stabilities of high-capacity noncarbon electrodes.

\subsubsection{Interfacial Modulation}

For the construction of carbon-noncarbon hybrid electrode materials for LIBs, the interfacial design and the carbon-noncarbon interaction model following assembly of the active materials into various kinds of carbon matrix (such as CNTs [79], graphene sheets [80], amorphous carbon layers [81], or graphitic carbon [82]), greatly influence charge transport and the structural stability of the hybrid. For a battery, fast electron transport is a vital factor for high electrical performance. Normally, to improve the conductivities of noncarbon materials, carbon supports or coatings are introduced, after which carbon-noncarbon hybrids with inner fast electron highways are formed. As a typical example, the conventional conductive carbon additives (carbon black and conducting graphite) used to improve electron transport in electrodes rely on the formation of model "point-to-point" contacts, whereas our group developed a "plane-to-point" contact model using 2D graphene as the conductive additive, which greatly promotes the electrochemical performance of low-conductivity noncarbon electrodes [83]. Furthermore, to avoid steric effects during ion diffusion in 2D graphene, especially for thick electrodes, a combination of "point-to-point" and "planeto-plane" contact models can be used to form a synergistic conductive network for noncarbon materials [84].

Apart from the above-mentioned two contact conductive models involving carbons and noncarbons, face-to-face interactions also play critical roles in enhancing the electrochemical performance of noncarbon anodes. Typically, face-to-face interactions between 2D Si nanosheets and thin carbon layers provided excellent electronic/ionic pathways as well as good structural stabilities, leading to improved lithium-ion storage performance [85]. For instance, layers of Si were deposited onto 3D graphene/CNT aerogels (CAs) to form Si/CA nanohybrids through simple CVD processes [86]. In these Si/CA nanohybrids, face-to-face contacts between $\mathrm{Si}$ and graphene led to rapid electronic/ ionic transfer and create sufficient voids, which contributed to high structural integrity. Therefore, compared with a Si/graphene-CNT mixture, this Si/CA nanohybrid delivered much higher reversible capacity (1498 $\mathrm{mAh} \mathrm{g}^{-1}$ at $200 \mathrm{~mA} \mathrm{~g}^{-1}$ ) and a more remarkable rate capability (462 $\mathrm{mAh} \mathrm{g}^{-1}$ at $10 \mathrm{~A} \mathrm{~g}^{-1}$ ). Moreover, to increase the mass content of the active materials and the stabilities of highcapacity anodes, Kong et al. developed a novel "side-toface" contact model, in which electrochemically active molybdenum disulfide $\left(\mathrm{MoS}_{2}\right)$ nanosheets directly stood on the inner surfaces of graphitic nanotubes, thereby forming mechanically robust, free standing, and interwoven $\mathrm{MoS}_{2} @ \mathrm{G}$ nanocable webs (Fig. 4a-e) [87]. The effective interfacial contact between the $\mathrm{MoS}_{2}$ nanosheets and the graphitic nanotubes not only realized full use of the active substance $\left(\mathrm{MoS}_{2}\right)$, but also facilitated the use of less carbon without the degradation of electrical performance, even at ultrahigh $\mathrm{MoS}_{2}$ content (90\%). Remarkably, a high specific capacity of $1150 \mathrm{mAh} \mathrm{g}^{-1}$, an excellent cycling capability ( $\sim 100 \%$ capacity retention after 160 cycles), and an ultrahigh rate performance of $700 \mathrm{mAh} \mathrm{g}^{-1}$ at a current density of $10 \mathrm{~A} \mathrm{~g}^{-1}$ were obtained using this $\mathrm{MoS}_{2} @ \mathrm{G}$ hybrid material with such a high $\mathrm{MoS}_{2}$ loading. To buffer dramatic volume expansion and further improve the volumetric performance of high-capacity noncarbons, Son et al. reported dynamic interfacial interactions between graphene and Si nanoparticles (Fig. 4f-h) [88]. In this work, a structure in which graphene layers were anchored onto a $\mathrm{Si}$ surface $(\mathrm{Gr}-\mathrm{Si}$ NPs) was obtained by employing the CVD approach, which introduced a novel graphene-interlayer sliding process that buffered Si expansion upon lithiation and delithiation. With this dynamic encapsulation, the well-defined conductive graphene coating enabled fast electron transport, while the layered graphene structure also relieved volume expansion to a large extent. Consequently, it exhibited a high volumetric energy density of $700 \mathrm{Wh} \mathrm{L}^{-1}$ even after 200 cycles, which was 1.5 times higher than that of a graphite-based control cell $\left(471 \mathrm{Wh} \mathrm{L}^{-1}\right)$. 


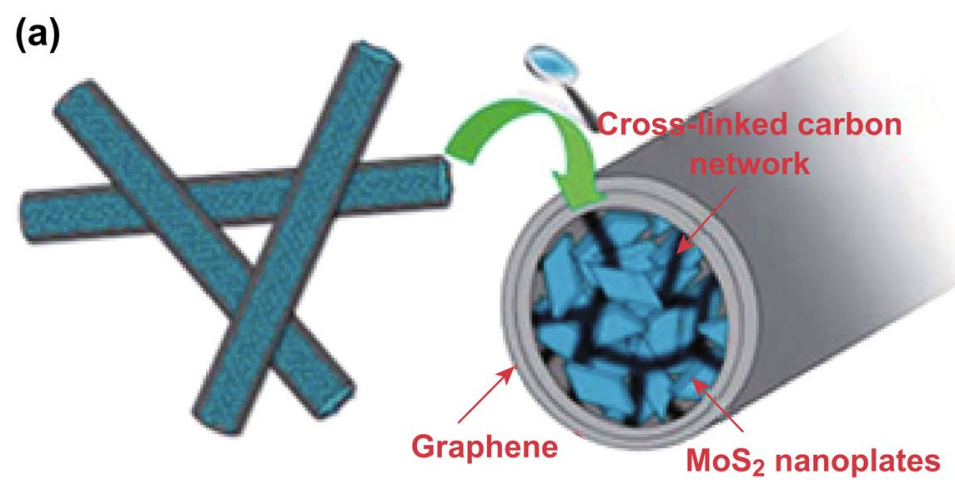

(b)

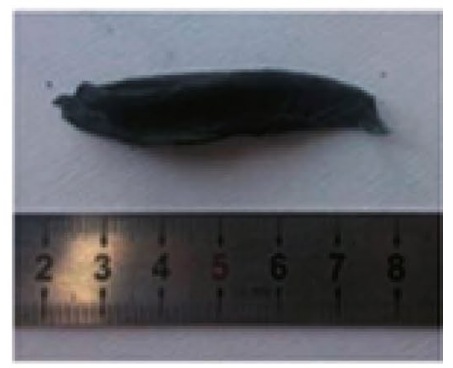

(c) $\quad \mathrm{Mo}^{-\mathrm{SiO}_{2}-\mathrm{PVP}}$

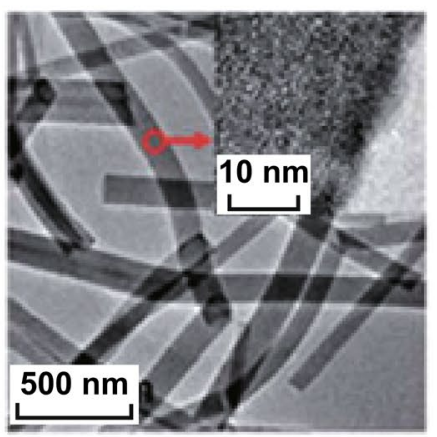

(d) $\mathrm{Mo-SiO}{ }_{2} @ G$

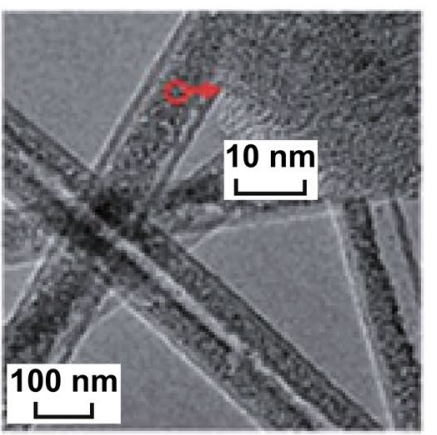

(e)

$\mathrm{MoS}_{2} @ \mathrm{G}$

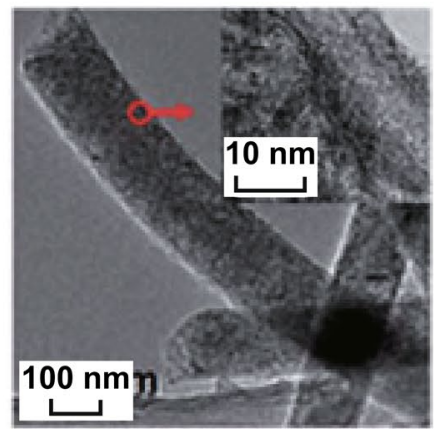

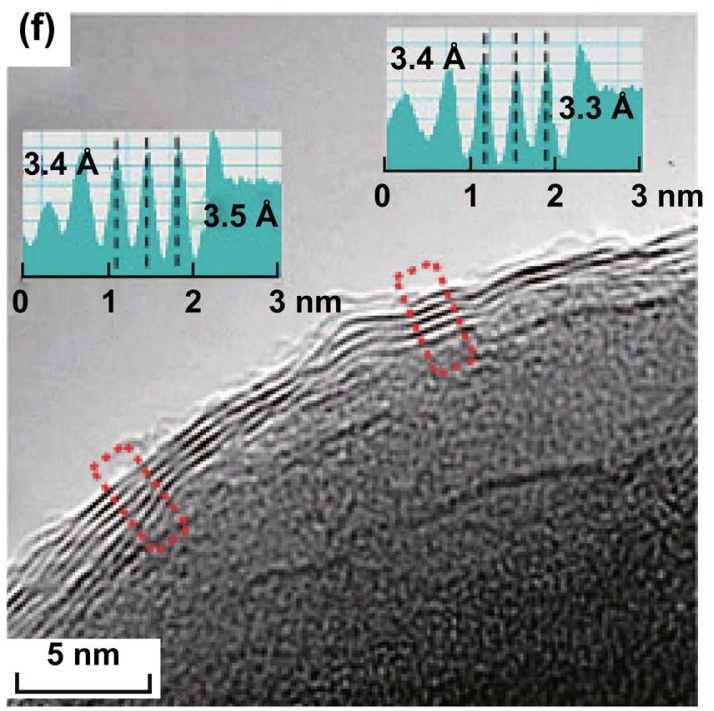

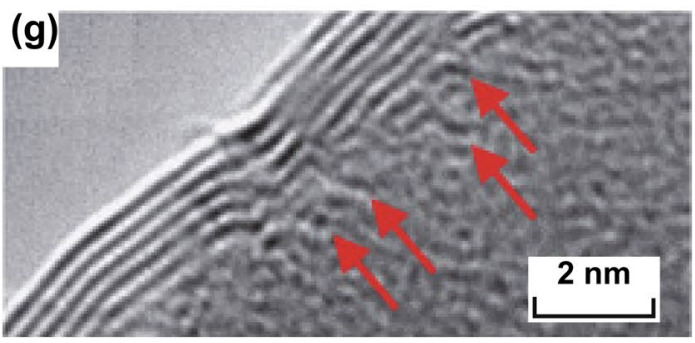

(h)

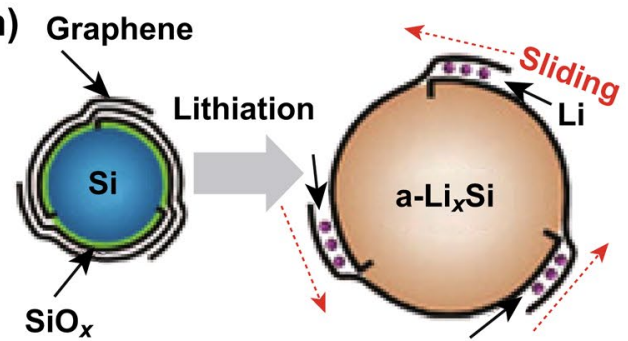

Fig. 4 a Schematic of $\mathrm{MoS}_{2} @ \mathrm{G}$. b Free-standing $\mathrm{MoS}_{2} @ \mathrm{G}$ membrane. SEM images of c Mo-SiO $-\mathrm{PVP}, \mathbf{d} \mathrm{Mo}-\mathrm{SiO}_{2} @ \mathrm{G}$, and e MoS $@ \mathrm{G}$. Reprinted with permission from Ref. [87]. f HRTEM image of Gr-Si NP. g HRTEM image visualizing the origins (red arrows) of individual graphene-layer growth. $\mathbf{h}$ Schematic illustration showing the sliding of graphene coating layers that buffer the volume expansion of Si. Reprinted with permission from Ref. [88]

\subsubsection{Network Skeleton Design}

Besides interfacial interactions as factors in carbon architecture design, the formation of a continuous carbon network is also of critical significance for facilitating ion and electron transport, and for buffering volume expansion involving noncarbon particles. In particular, to solve the challenges of poor charge transport and huge volume fluctuation in 
dense and thick electrodes, a variety of carbon networks with directional, graded, and hierarchical features have been rationally designed for high-capacity noncarbon electrodes in recent research.

As discussed above for the directional assembly of active carbon materials, the directional transport of ions can also be achieved in carbon-noncarbon electrodes by vertically constructing a carbon network. Several pieces of work have been devoted to the design and synthesis of vertically aligned graphene arrays (VAGAs) [19] or graphene-based arrays, such as Si NPS@graphene nanosheets [89], germanium oxide $\left(\mathrm{GeO}_{\mathrm{x}}\right)$ on VAGAs [90], tin@ graphene (Sn@G) on VAGAs [91], and $\mathrm{MoS}_{2}$ on vertical graphene nanosheets (VGNS) [92], for use in LIBs. Typically, the vertically aligned $\mathrm{MoS}_{2} /$ VGNS nanostructure [92], fabricated through CVD and solvothermal processes, showed a high specific capacity (1277 $\mathrm{mAh} \mathrm{g}^{-1}$ at $\left.100 \mathrm{~mA} \mathrm{~g}^{-1}\right)$ and excellent cycling stability (1109 $\mathrm{mAh} \mathrm{g}^{-1}$ after 100 cycles). This excellent electrochemical performance mainly originated from the directional carbon-based architecture, which not only provided fast electron and lithium-ion diffusion pathways, but also achieved stable structural integrity during cycling.

Compared to the design of homogeneous electrodes, producing a functionally layer-graded electrode is another effective strategy for promoting charge-carrier transport. Zhang et al. demonstrated a functionally layer-graded electrode composed of titanium dioxide (B) and multilayered rGO nanotubes that reduced the charge-transport barrier [93]. Consequently, this layer-graded electrode showed a much higher rate performance $\left(128 \mathrm{mAh} \mathrm{g}^{-1}\right.$ at $\left.20 \mathrm{C}\right)$ compared with a traditional homogeneous electrode $\left(74 \mathrm{mAh} \mathrm{g}^{-1}\right.$ at 20 C) on account of the synergism between the reduction in the lithium-ion diffusion energy barrier and the improvement in electronic conductivity.

Multiple hierarchical core/shell directional arrays composed of two or more components, in which 2D building blocks were vertically grown on $2 \mathrm{D} / 3 \mathrm{D}$ conductive substrates that can serve as self-supported electrodes, were fabricated to ensure charge delivery across the whole electrode. Firstly, direct contact between the active components and the surfaces of conductive substrates guarantees rapid electron transfer. Additionally, the gap between each array accommodates large volume expansion and contraction upon lithiation and delithiation. Using a simple surfactantassisted hydrothermal method combined with post-annealing treatment, Shen et al. synthesized a structure composed of mesoporous nickel cobaltate $\left(\mathrm{NiCo}_{2} \mathrm{O}_{4}\right)$ nanowire arrays (NWAs) anchored on carbon textiles [94]. When directly used as a binder-free electrode in a lithium-ion battery, this flexible $\mathrm{NiCo}_{2} \mathrm{O}_{4} /$ carbon composite textile exhibited high capacity (1012 $\mathrm{mAh} \mathrm{g}^{-1}$ at $0.5 \mathrm{~A} \mathrm{~g}^{-1}$ ), good cycling stability (retaining $854 \mathrm{mAh} \mathrm{g}^{-1}$ at $0.5 \mathrm{~A} \mathrm{~g}^{-1}$ after 100 cycles), and excellent rate performance $\left(778 \mathrm{mAh} \mathrm{g}^{-1}\right.$ at $\left.2 \mathrm{~A} \mathrm{~g}^{-1}\right)$. The excellent performance of this composite textile was mainly ascribable to the ample mesoporous structure of the nanowire array and the large open spaces between neighboring nanowires, which ensured that all nanowires participate in ultrafast electrochemical reactions and alleviated volume changes during the charge/discharge processes. Wang et al. presented a strategy that involves patterning vertical $\mathrm{MoS}_{2}$ nanosheets onto electrochemically exfoliated graphene (EG) to achieve a hierarchical architecture [95]. Using synergism between the vertically aligned structure and the $2 \mathrm{D}$ geometry, this structure exhibited high mechanical integrity and fast charge-transport kinetics. When serving as an anode material in a lithium-ion battery, it delivered an ultrahigh specific capacity of $1250 \mathrm{mAh} \mathrm{g}^{-1}$ after 150 stable cycles at $1 \mathrm{~A} \mathrm{~g}^{-1}$, excellent rate performance of $970 \mathrm{mAh} \mathrm{g}^{-1}$ at $5 \mathrm{~A} \mathrm{~g}^{-1}$, and a high areal capacity of $1.27 \mathrm{mAh} \mathrm{cm}^{-2}$ at $\sim 1 \mathrm{~mA} \mathrm{~cm}^{-2}$.

The assembly of holey or porous carbon building blocks into hierarchical networks plays a significant role in enhancing ion-transport kinetics for thick electrodes upon cycling. For example, Wang et al. synthesized a 3D carbon nanosheet array/MnO hybrid (3D-MnO/CNS). MnO nanocrystallites were mechanically anchored in this unique structure by the pore-surface terminations of the 3D arrays of graphene-like carbon nanosheets, resulting in both fast electron transport and a 20 -nm-scale diffusion distance in this interlinked architecture. As a result, a high lithium storage capacity (1332 $\mathrm{mAh} \mathrm{g}^{-1}$ at $0.1 \mathrm{~A} \mathrm{~g}^{-1}$ ) and a high rate performance (285 $\mathrm{mAh} \mathrm{g}^{-1}$ at $20 \mathrm{~A} \mathrm{~g}^{-1}$ ) were delivered, with stable cycling performance (500 cycles) [96]. To promote the use of nanostructured electrodes in high-energy and high-power LIBs, Sun et al. reported the design of a 3D holey-graphene/ niobia $\left(\mathrm{Nb}_{2} \mathrm{O}_{5}\right)$ composite for ultrahigh rate energy storage at practical levels of mass loading $\left(>10 \mathrm{mg} \mathrm{m}^{-2}\right)$ [97]. As shown in Fig. 5a, the two-step process for the preparation of the free-standing $\mathrm{Nb}_{2} \mathrm{O}_{5} / \mathrm{HGF}$ composite included the preparation of building blocks and the assembly of these blocks into the 3D holey monolithic composite (Fig. 5b). The pore size of the GO plane can be easily tuned by changing the 

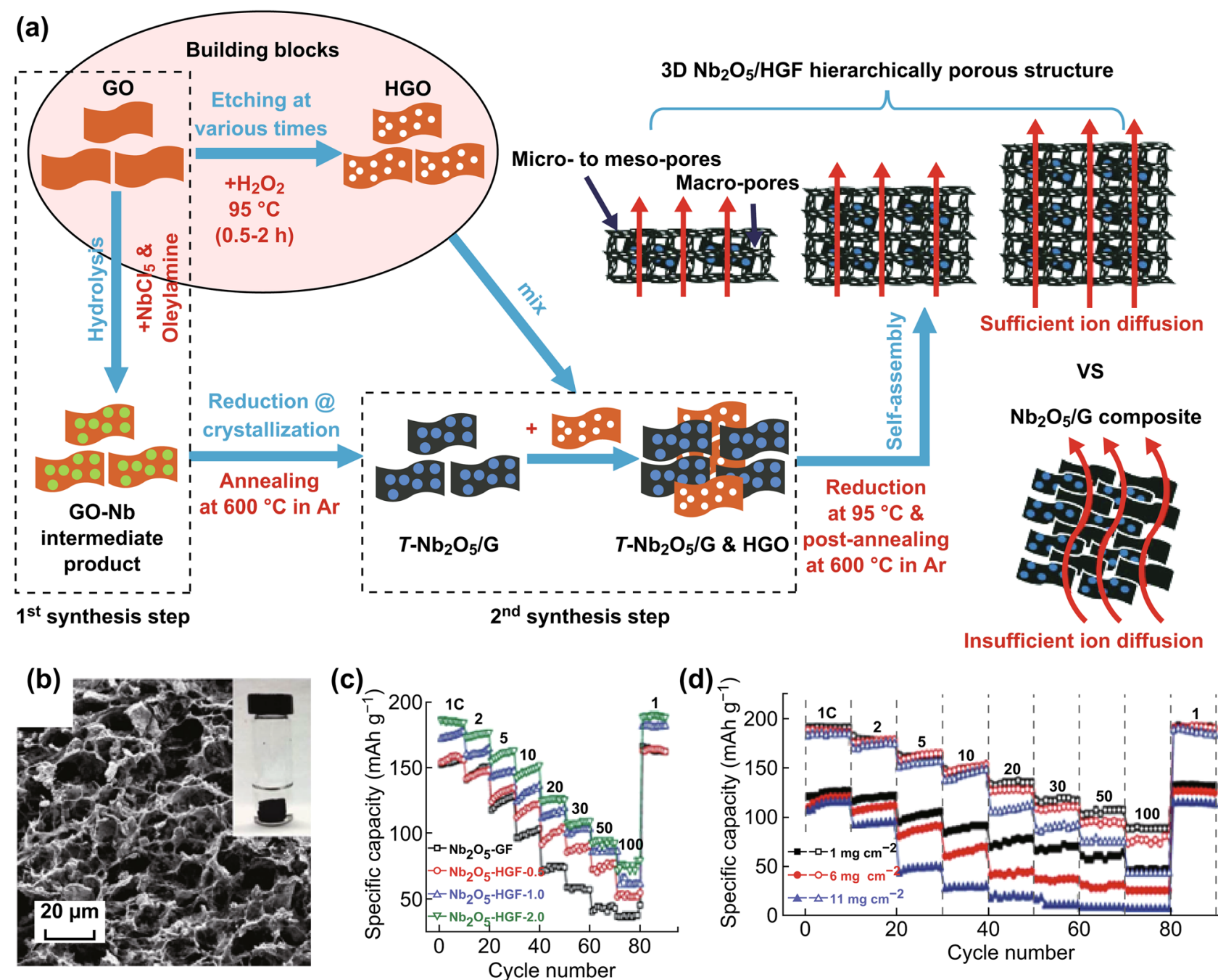

(c)

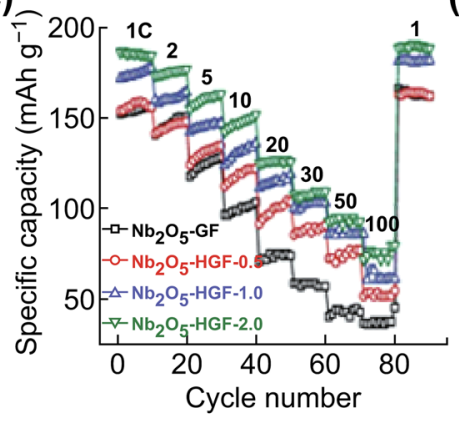

(d)

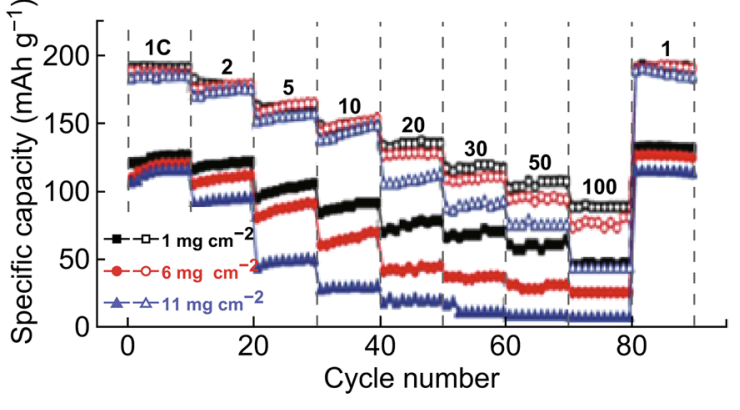

Fig. 5 a Schematic of the fabrication process. b Cross-sectional SEM image. (Inset) A free-standing monolithic electrode. c Rate capability at tunable nanoporosity. d Rate performance at different mass loadings. Reprinted with permission from Ref. [97]

$\mathrm{H}_{2} \mathrm{O}_{2}$-etching time, thereby providing suitable ion pathways. In this hybrid material, the 3D graphene network provided an interconnected conductive network, and its hierarchical porous structure facilitated rapid ion transport and mitigated diffusion limitations throughout the entire electrode architecture. There was little difference in specific capacity for mass loadings ranging from 1 to $11 \mathrm{mg} \mathrm{cm}{ }^{-2}$ at rates as high as $10 \mathrm{C}$ (Fig. 5c-d). Promisingly, the $\mathrm{Nb}_{2} \mathrm{O}_{5} / \mathrm{HGF}$ composite electrode showed high areal capacity with high rate capability at large mass loadings, which represented a critical step toward the practical application of high-power-density LIBs.

The construction of hierarchical carbon networks can greatly alleviate volume variations of the noncarbon components and help to avoid side reactions with the electrolyte.
Liu et al. presented a classic "pomegranate"-like hierarchical Si structure, which effectively tackled the major problems of structural failure, the repetitive formation of solid electrolyte interface (SEI) layers, and the low volumetric capacities of $\mathrm{Si}$ anodes [30]. Recently, Xu et al. designed and synthesized hierarchical $\mathrm{Si} / \mathrm{C}$ hybrids inspired by the structure of watermelon fruit [98]. Due to the dual protection strategy of a hierarchically structured buffer and an optimized particle-size distribution, this $\mathrm{Si} / \mathrm{C}$ anode afforded excellent electrochemical performance, including a superior average coulombic efficiency of $99.8 \%$ during early cycles, and a good cyclic life of 500 cycles under practical mass loadings and pressing densities. 


\subsubsection{Void Space Manipulation}

To address the problem of volume expansion, the design of the void space in a carbon-noncarbon hybrid structure is critically important. Tremendous work has focused on fabricating hollow structures, such as C@manganese oxide $\left(\mathrm{MnO}_{2}\right)$ yolk-shelled spheres [35] and multi-shelled nickel sulfide (NiS) nanoboxes [99]. Typically, $\mathrm{Fe}_{3} \mathrm{O}_{4} @$ iron carbide $\left(\mathrm{Fe}_{3} \mathrm{C}\right) @ \mathrm{C}$ yolk-shelled nanospindles were synthesized using a one-step in situ nanospace-confined pyrolysis strategy involving $\mathrm{Fe}_{2} \mathrm{O}_{3} @$ resorcinol-formaldehyde (RF) core@ shell nanospindles [100]. This unique structure provided sufficient internal void space for electrochemically active $\mathrm{Fe}_{3} \mathrm{O}_{4}$ and afforded a $\mathrm{Fe}_{3} \mathrm{C} / \mathrm{C}$ dual shell that restricts $\mathrm{Fe}_{3} \mathrm{O}_{4}$ dissolution. Consequently, this nanospindle exhibited a high reversible capacity of $1128 \mathrm{mAh} \mathrm{g}^{-1}$ in a lithium-ion battery. Compared to typical yolk spheres, the yolks in polyhedral shells had larger contact areas that facilitated conducting electrons and diffusing ions. Zhang et al. synthesized a yolk Sn@C nanobox composite with controllable shell thickness by a novel method [101]; zinc stannate $\left(\mathrm{ZnSnO}_{3}\right)$ nanocubes as precursors were uniformly coated with polydopamine (PDA), after which they thermally treated to carbonize the PDA and reduce $\mathrm{ZnSnO}_{3}$ to metallic $\mathrm{Zn} / \mathrm{Sn}$ in situ. After evaporation of the low-boiling Zn, a yolk-shell Sn@C nanobox was finally produced. The void space was easily tuned to fit the volume expansion of Sn during lithiation and delithiation by controlling the concentration of PDA. Thus, with a suitable shell thickness, the resulting composite exhibited a high reversible capacity of $810 \mathrm{mAh} \mathrm{g}^{-1}$, even after 500 cycles, and benefited from a sufficient buffer for volume change during cycling. To solve the structural fracturing of micro-Si particles, $\mathrm{Li}$ et al. fabricated a unique $\mathrm{Si} / \mathrm{C}$ hybrid microparticle in which mechanically strong and flexible graphene cages completely encapsulate micrometer-sized $\mathrm{Si}$ particles [102]. During preparation, a dual-purpose Ni template acted as both the catalyst for graphene growth and the sacrificial layer that provided void space. The graphene cage not only possessed excellent electrical conductivity and adequate buffer space, but also promised electrical connectivity for fractured $\mathrm{Si}$ microparticles after repeated lithiation. In addition, efficient SEI formation on the surface of the graphene cage minimized irreversible lithium ion losses, leading to high coulombic efficiencies $(93.2 \%$ and $99.9 \%$ respectively) during initial and subsequent cycles. When paired with a traditional lithium cobalt oxide (LCO) cathode, the graphene-caged Si microparticles showed excellent stable cycling (100 cycles; $90 \%$ capacity retention) during full-cell electrochemical testing.

Except for the synthesis of carbon cages or shells that surround single electroactive particles, the fabrication of 3D interconnected porous carbon structures is another common strategy for introducing void space. Jung et al. synthesized a Si-carbon composite ( $\mathrm{Si} @$ po-C) using an industrially established spray-drying process, in which Si nanoparticles were uniformly distributed in porous carbon spheres [103]. The porous structures inside the carbon spheres provided void space for the volume expansion of $\mathrm{Si}$, as well as improved electrical and ionic conductivity, which was conducive to excellent electrochemical performance, including $1956 \mathrm{mAh} \mathrm{g}^{-1}$ at a $0.05 \mathrm{C}$ rate and a $91 \%$ capacity retention after 150 cycles.

Several pieces of advanced work have focused on 3D freestanding structures that can be directly used as binder-free electrodes. For example, Mo et al. developed a 3D interconnected porous nitrogen-doped graphene foam (NGF) with an encapsulated Ge quantum-dot@nitrogen-doped graphene yolk-shell nanoarchitecture [104]. This unique 3D nanoarchitecture not only afforded internal void space for accommodating the huge volume change of Ge during cycling, but also provided ample channels for access to the electrolyte, an interconnected conductive network, and fast lithium-ion diffusion pathways (Fig. 6). Hence, this 3D yolk-shell nanoarchitecture exhibited excellent electrical performance, including a high specific reversible capacity of $1220 \mathrm{mAh} \mathrm{g}^{-1}$, long-cycling capability (over $96 \%$ capacity retention from the second to the 1000th cycle), and an ultrahigh rate performance (over $800 \mathrm{mAh} \mathrm{g}^{-1}$ at $40 \mathrm{C}$ ). Ma et al. encapsulated Si nanoparticles into highly oriented graphene foam (GF) using a freeze-drying method [105]. Rich inner pores in the GF promised well-accessible channels for electrolyte penetration and electron/ion transportation; they also tackled the issues of huge volume changes and mechanical instability during charge/discharge processes. Consequently, this GF/Si composite displayed stable cycling performance in both half-cell (retaining $1170 \mathrm{mAh} \mathrm{g}^{-1}$ at $1 \mathrm{~A}$ after 1200 cycles) and full-cell (90\% capacity retention over 200 cycles) configurations. 

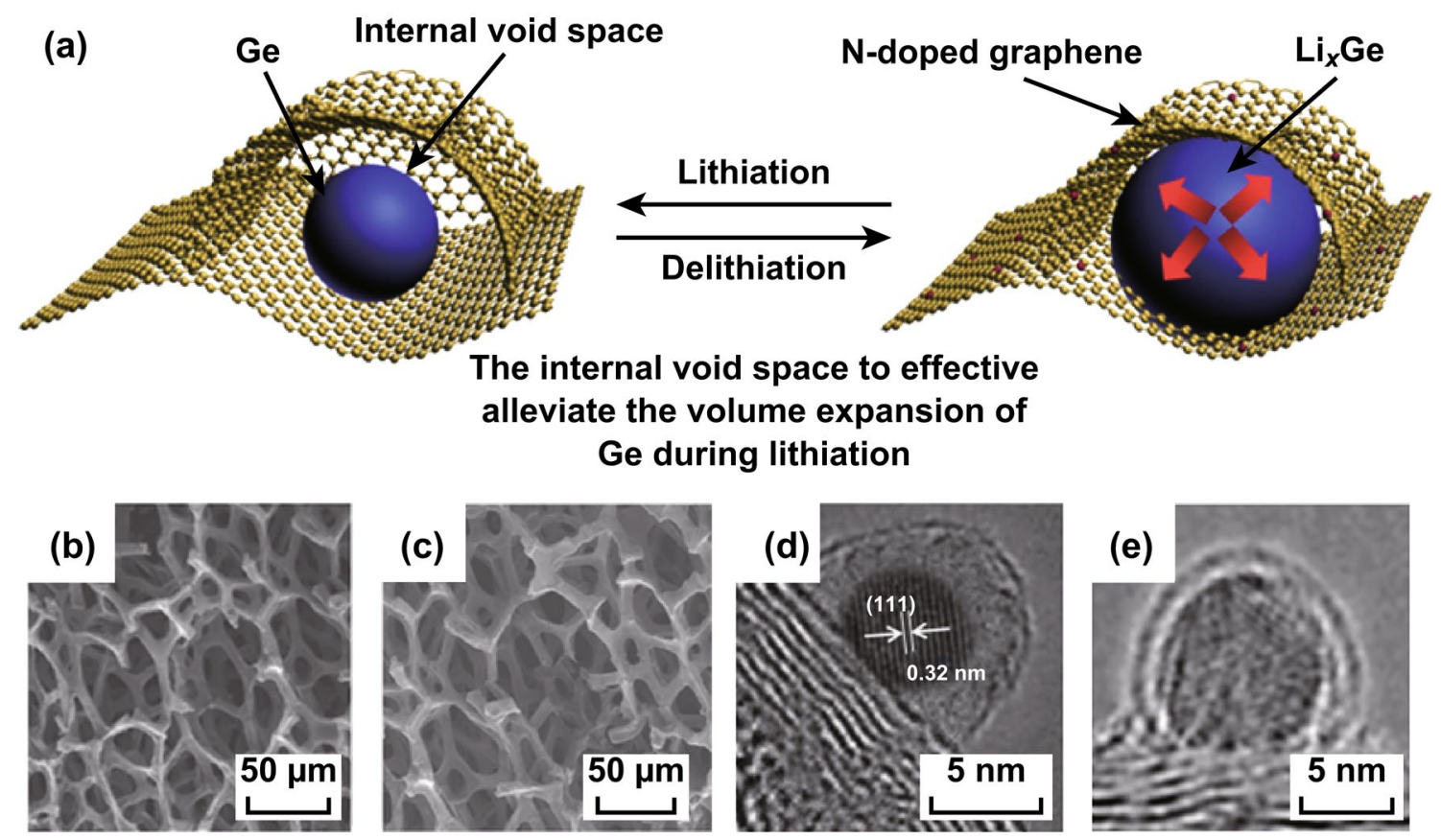

Fig. 6 a Schematic of the lithiation/delithiation processes of the Ge-QD@NG/NGF/PDMS yolk-shell electrode. b, c SEM and d, e TEM images before cycling and under lithiation after 1000 cycles at a current density of $1 \mathrm{C}$. Reprinted with permission from Ref. [104]

\subsubsection{Densification Engineering}

The nanostructured carbons used for electrode construction can significantly improve mass-based capacity and rate performance, but unfortunately, they usually lead to low volume-based capacities due to the low densities of carbonbased active materials [15]. Meanwhile, the abundant void spaces introduced into the carbon architectures to buffer the volume expansion of noncarbons makes it difficult to attain high volumetric performance. As a result, those nanostructures with high mass capacities but low packing densities deliver low specific volumetric energy densities, which limit their practical applications. The main remedy for this issue involves increasing the particle size of the electroactive material to avoid low tap density [106]. Much research has focused on building secondary structures composed of agglomerated nanosized primary particles based on carbon assemblies, which are capable of not only achieving high electrode density, but also preserving the electrochemical properties of the nanosized active materials [107].

For example, by using graphene oxide (GO) as both hard and soft templates [22], our group fabricated a high packing density $\left(1.35 \mathrm{~g} \mathrm{~cm}^{-3}\right)$ ferric oxide/graphene microparticle hybrid $\left(\mathrm{Fe}_{2} \mathrm{O}_{3}-\mathrm{G}\right)$ [108]. Two-dimensional GO sheets provided abundant nucleation sites for $\mathrm{Fe}_{2} \mathrm{O}_{3}$ growth and the formation of $\mathrm{Fe}_{2} \mathrm{O}_{3}$ microspheres, and hydrothermal treatment afforded a 3D interconnected graphene conductive framework for embedded $\mathrm{Fe}_{2} \mathrm{O}_{3}$ microspheres (Fig. 7a). This $\mathrm{Fe}_{2} \mathrm{O}_{3}$ - $\mathrm{G}$ microsphere design not only provided an efficient conductive network and sufficient void space to alleviate large $\mathrm{Fe}_{2} \mathrm{O}_{3}$ volume changes, but it also ensured high material tap densities. As a result, these $\mathrm{Fe}_{2} \mathrm{O}_{3}$-G microspheres concurrently delivered a high capacity, excellent rate performance, and a super-high volumetric capacity of about $1200 \mathrm{mAh} \mathrm{cm}^{-3}$ (three times that of a commercial graphite anode $\left.\left(370 \mathrm{mAh} \mathrm{cm}^{-3}\right)\right)$.

Nanosized spinel cathode (LMO) materials possess good intrinsic rate capabilities but cannot fulfill the requirements of high electrode densities and volumetric energy densities. Carbon coating has been widely used to increase electronic conductivity, but traditional carbon coating by the pyrolysis of organic compounds or CVD on the LMO surface unavoidably always produces oxygen defects, which leads to a blocked rate capability. To solve this problem, Lee et al. fabricated spherical secondary particles composed of acidtreated Super P (ASP) and nanosized LMO primary particles using a water-based spray-drying process, referred to as "ASPLMO" [16]. In this composited material, the nanosized 


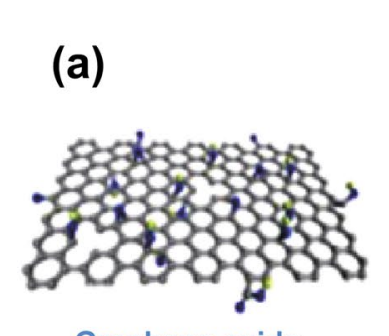

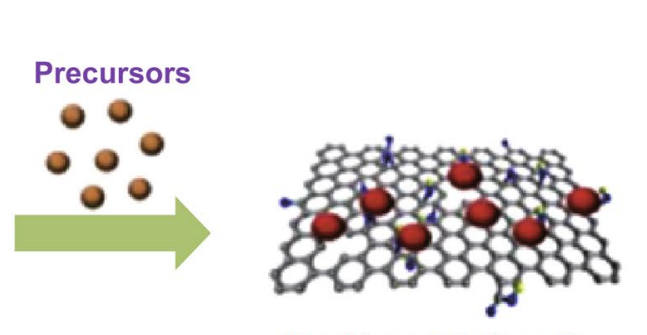

Hard template function
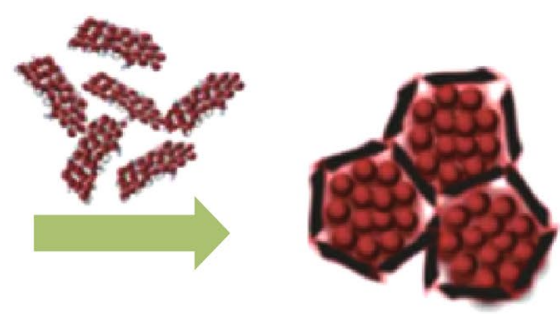

Soft template function

(b)
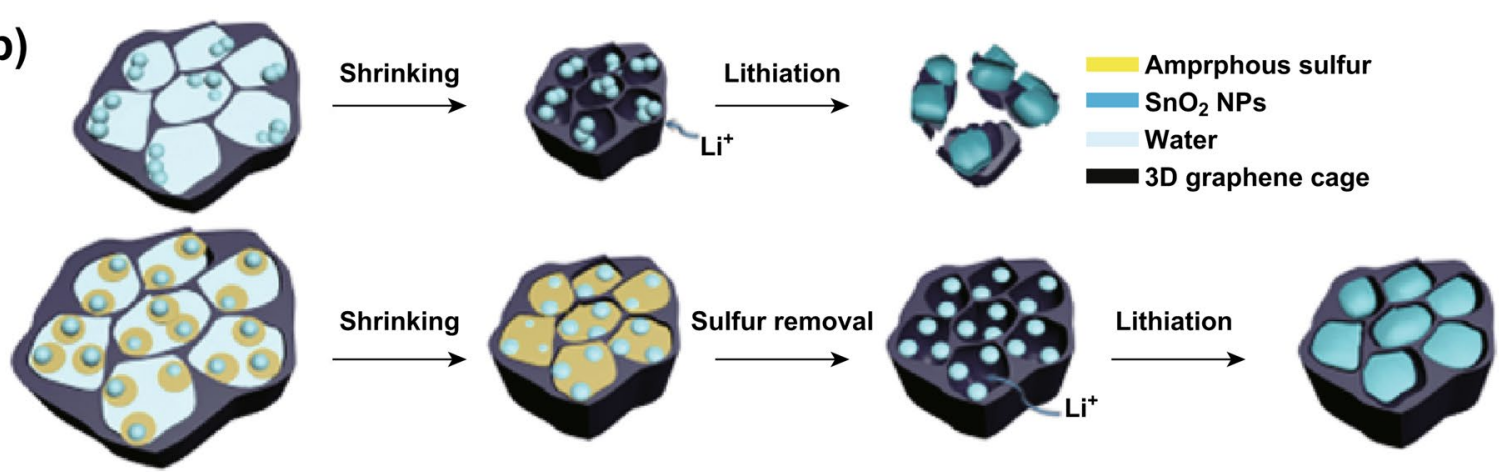

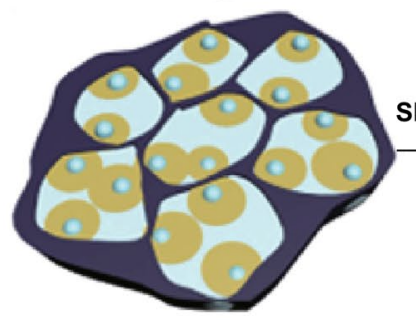

(c)

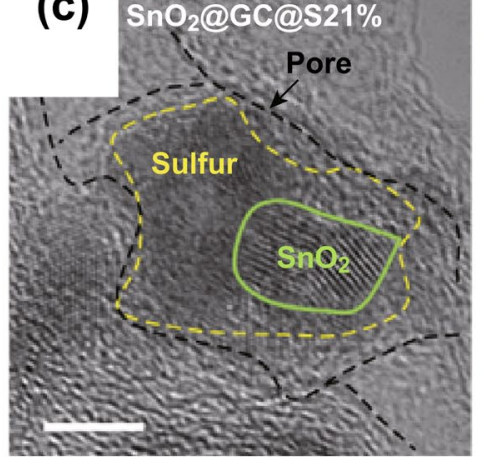

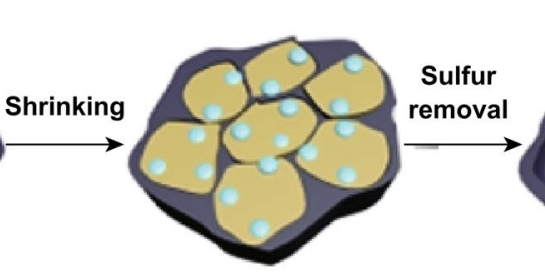

(d)

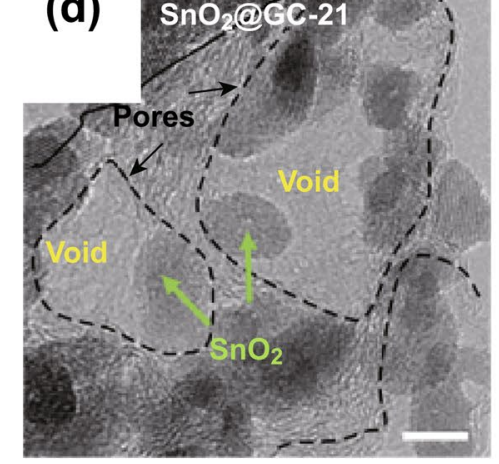

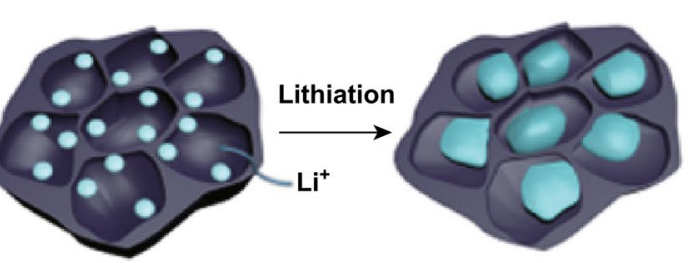

๓

(e)

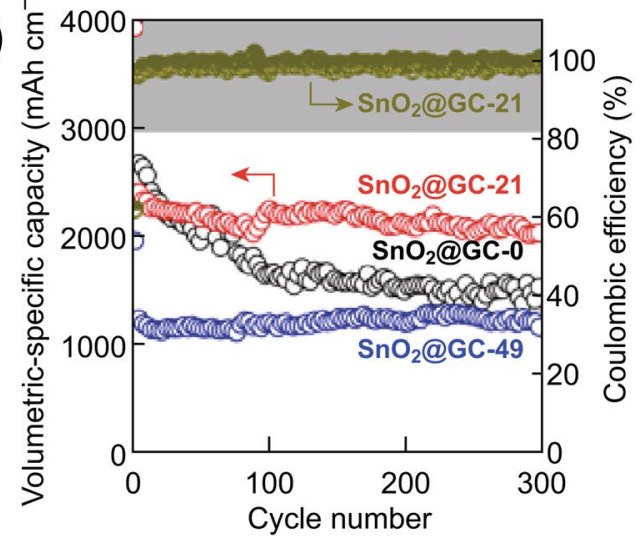

Fig. 7 a Schematic of in situ nanocrystal growth with GO as both hard and soft templates. Reprinted with permission from Ref. [108]. b Schematic of the sulfur-template control strategy that incorporates void space. HRTEM image of SnO $@$ @C: c before sulfur removal and d after removal of all of the original sulfur (Scale bar: $5 \mathrm{~nm}$ ). e Cycling performance. Reprinted with permission from Ref. [113]

LMO primary particles ensured fast lithium-ion diffusion and uniformly dispersed conductive pathways, while the microsized structure $(7-40 \mu \mathrm{m})$ guaranteed a high electrode density $\left(2.4 \mathrm{~g} \mathrm{~cm}^{-3}\right)$. Consequently, this ASPLMO material exhibited a volumetric energy density of $270 \mathrm{Wh} \mathrm{L}^{-1}$ at a power density of $780 \mathrm{~kW} \mathrm{~L}^{-1}$. Through a one-pot mixed-solvothermal process followed by direct calcination, Wang et al. synthesized $\mathrm{LiFePO}_{4} @$ carbon/rGO hierarchical microspheres [109] that exhibited a high tap density of $1.3 \mathrm{~g} \mathrm{~cm}^{-3}$, while the carbon layers coated on $\mathrm{LiFePO}_{4}$ primary nanocrystals and ultrathin rGO nanosheets anchored on the surface simultaneously provided fast electron/ 
lithium-ion transport, resulting in excellent rate capability and cycling stability.

Apart from the increase in the particle size of the active material, the densification of carbon network and the hybridization of high-density and high-capacity noncarbons are further simple but effective strategies for improving the packing densities of carbon-based electrode materials [110, 111]. The compact assembly of graphene, free of inter-particle voids, has shown great potential for high volumetric energy storage [112]. As a typical example, a hybrid hydrogel of a noncarbon ( $\mathrm{Sn}$ and Si-based particles) and a 3D graphene network was synthesized by a hydrothermal process; this hydrogel was subsequently treated by capillary drying to achieve shrinkage, to yield a 3D ultrahigh-density assembly. This method can easily be extended to the densification of graphene-based materials derived from hydrogels; however, it is difficult to ensure that sufficient void space is left for noncarbon-particle expansion upon lithiation. Recently, our group chose sulfur as a flowable template for the preparation of a tin oxide@graphene cage hybrid $\left(\mathrm{SnO}_{2} @ \mathrm{GC}\right)$ with a high packing density, yet well-defined void space (Fig. 7b-d) [113]. Smart sulfur can seamlessly encapsulate noncarbon particles following the capillary drying of graphene hydrogels. The content of this sacrificial sulfur agent can be used to precisely adjust the quantity and sizes of the pores, resulting in different sizes of carbon cages following sulfur removal. When used as an anode material in a lithium-ion battery, the resultant graphene-caged $\mathrm{SnO}_{2}$ afforded a high specific capacity of $974 \mathrm{mAh} \mathrm{g}^{-1}$ and an ultrahigh volumetric capacity of $2123 \mathrm{mAh} \mathrm{cm}^{-3}$, together with a long cycle life (300 cycles) and limited change in electrode thickness $(<20 \%)$ (Fig. 7e). Our result suggests that this general strategy of precisely tailoring the buffer space in a carbon cage not only provides sufficient voids for volume change, but also engineers the packing density to produce high energy storage capabilities in small volumes.

\subsection{Highly Contacted Carbon-Based Current Collectors}

Besides focusing on accelerating charge-carrier transport and enhancing structural stability at the electrochemically active material level by the carbon assembly strategy, the design of carbon architectures as current collectors also contributes to improving electrochemical performance. Well-assembled lightweight carbon architectures can afford stronger interfacial interactions, larger contact areas, and greater charge delivery at both the active material and electrode level than conventional copper $(\mathrm{Cu})$ and aluminum (Al) current collectors, which is highly desirable for improving specific capacity, rate performance, and structural stabilities of high-capacity noncarbon electrodes.

A few strategies have been developed to maintain strong electrical connections and achieve fast electron/ion transport inside an electrode, by engineering carbon materials into current collector matrixes [114]. Rather than traditional $\mathrm{Cu}$ or $\mathrm{Al}$ current collectors, carbon-based current collectors are lighter and more flexible. For example, Wu et al. fabricated a CNT woven macrofilm (CMF) that acted as current collector through methanol-mediated CVD [115]. The active materials were permeated into the surface of the CMF, thereby alleviating delamination under ultrahigh mass loadings $\left(10 \mathrm{mg} \mathrm{cm}^{-2}\right.$ ) and contributing to a high-energy density of $215 \mathrm{mWh} \mathrm{cm}^{-3}$.

Recently, 3D porous current collectors, instead of 2D planar current collectors, have attracted much attention for the preparation of free-standing and lightweight lithium-ion electrodes, such as CNT sponge-based 3D electrodes [116] and graphene foam (DGF)-based 3D electrodes [12, 117, 118]. As a typical example, using a 3D GF as both current collector and substrate for $\mathrm{MoS}_{2}$ growth, an integrated electrode of honeycomb-like-molybdenum sulfide@GF (HC$\mathrm{MoS}_{2} @ \mathrm{GF}$ ) was fabricated [119]. Due to the direct contact and interconnection between the current and the active material, the HC-MoS $\mathrm{H}_{2} @ \mathrm{GF}$ exhibited high reversible capacity of $1235 \mathrm{mAh} \mathrm{g}^{-1}$ at $200 \mathrm{~mA} \mathrm{~g}^{-1}$ with excellent cycling stability. Inspired by the hierarchical porous structure of wood in nature [120], Chen et al. prepared a multi-channeled 3D carbon framework (CF) carbon-based current collector through the use of carbonized and activated multi-channeled natural wood (CA wood) (Fig. 8a, b) [121]. This 3D current collector displayed advantages of high electrical conductivity, low tortuosity, and lightweightness. By simple infiltration, the electroactive materials permeated into the channels of the $3 \mathrm{D}$ CF current collector to form an ultrahigh-mass-loaded and ultrathick (up to $800 \mu \mathrm{m}$ ) 3D electrode (Fig. 8c, d). Benefiting from its structural merits, this electrode exhibited significantly improved electronic and ionic kinetics; the ultrathick $3 \mathrm{D}$ electrode delivered a high capacity of $7.6 \mathrm{mAh} \mathrm{cm}^{-2}$ (95 

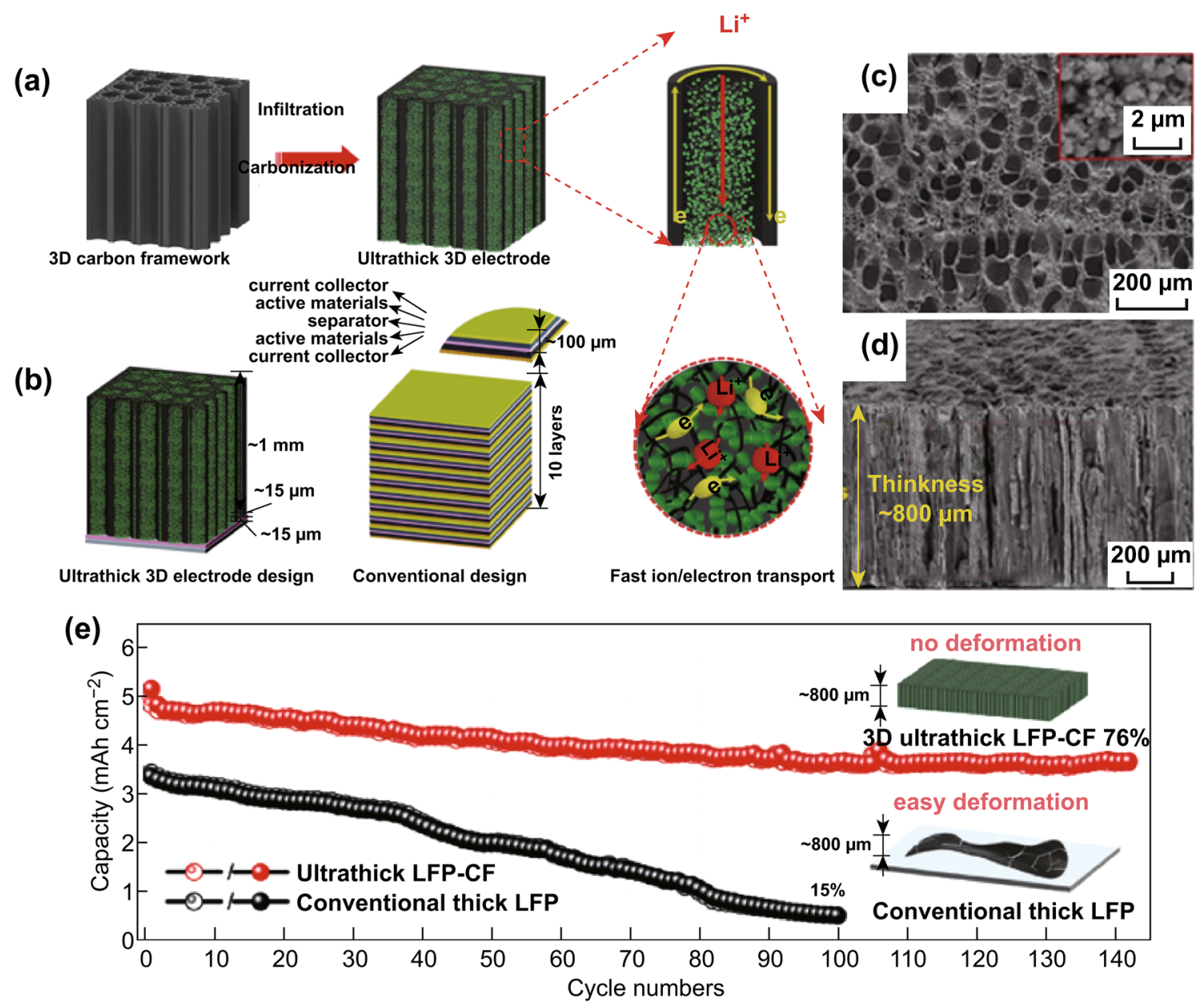

Fig. 8 a Design concept of a 3D carbon-based current collector. b Visual comparisons of batteries with an ultrathick 3D electrode and a conventional design. Morphology and microstructure: $\mathbf{c}$ top view and $\mathbf{d}$ cross-sectional view. e Electrochemical performance. Reprinted with permission from Ref. [121]

Ah $\mathrm{L}^{-1}$ based on volume) at $0.5 \mathrm{~mA} \mathrm{~cm}{ }^{-2}$, and an energy density of $26 \mathrm{mWh} \mathrm{cm}^{-2}$ (323 $\mathrm{Wh} \mathrm{L}^{-1}$ based on volume) (Fig. 8e). Moreover, this 3D electrode exhibited excellent cyclability and overall safety in terms of its low deformability and enhanced mechanical properties. On the other hand, efforts have been made to fabricate 3D metallic current collectors (e.g., 3D Cu current collectors [122] or Ni foam [123]), which have the advantages of facile fabrication, large surface areas, and high porosities. In addition, 3D metallic collectors with uniform and smooth porous structures have been used in lithium-based batteries [124]. In comparison with 3D metallic current collectors, the lightweight carbonaceous current collectors still possess more reliable chemical stabilities and excellent pore controllabilities on the multiscale, which contribute to their better performance.

\section{Conclusions and Prospects}

Engineering carbon electrodes is critical for fabricating both high energy density and power density LIBs. Nanostructured carbon-based electrodes hold great promise for enhancing electrochemical performance, which, unfortunately, is not readily scaled up to practical densities and thicknesses. Rationally assembled carbon architectures used in electrodes not only maintain the original nanoscale characteristics of each component, but also exploit synergism between different primary structures, thereby playing reinforcing roles in improving electrochemical performance under practical electrode conditions. As discussed in this review, a series of typical carbon architectures has been proposed to solve the problems of low electrical 
Table 1 Electrochemical performance of typical carbon architectures in lithium-ion batteries

\begin{tabular}{|c|c|c|c|c|c|}
\hline Samples & Assembly approaches & Capacity $\left(\mathrm{mAh} \mathrm{g}^{-1}\right)$ & $\begin{array}{l}\text { Cycle life } \\
\text { (capacity } \\
\text { retention\%) }\end{array}$ & Rate performance $\left(\mathrm{mAh} \mathrm{g}^{-1}\right)$ & $\overline{\text { References }}$ \\
\hline Si@void@C & Template and HF-etching & $\begin{array}{l}1160 \mathrm{mAh} \mathrm{g}^{-1} \\
(0.5 \mathrm{C})\end{array}$ & 1000 & - & {$[30]$} \\
\hline Si-NW/GNR paper & Vacuum-filtration & $\begin{array}{l}\approx 1500 \mathrm{mAh} \mathrm{g}{ }^{-1} \\
\left(1 \mathrm{~A} \mathrm{~g}^{-1}\right)\end{array}$ & 300 & & [41] \\
\hline LFP/GNR/G & $\begin{array}{l}\text { Spray deposition and } \\
\text { vacuum filtration }\end{array}$ & $\begin{array}{l}\sim 130 \mathrm{mAh} \mathrm{g}_{\text {electrode }}^{-1} \\
\text { (1C) }\end{array}$ & 500 & $118 \mathrm{mAh} \mathrm{g}_{\text {electrode }}^{-1}(5 \mathrm{C})$ & [42] \\
\hline $\mathrm{Fe}_{3} \mathrm{O}_{4} / \mathrm{rGO}$ paper & $\begin{array}{l}\text { Magnetic field assisted self- } \\
\text { assembly }\end{array}$ & $\begin{array}{l}1140 \mathrm{mAh} \mathrm{g}^{-1} \\
\left(0.15 \mathrm{~A} \mathrm{~g}^{-1}\right)\end{array}$ & 220 & $\sim 700 \mathrm{mAh} \mathrm{g}^{-1}(10 \mathrm{C})$ & {$[52]$} \\
\hline VA-CNTs/Si & MPECVD and HF-CVD & $\begin{array}{l}800 \mathrm{mAh} \mathrm{g} \mathrm{g}^{-1} \\
(10 \mathrm{C})\end{array}$ & 100 & $765 \mathrm{mAh} \mathrm{g}^{-1}(15 \mathrm{C})$ & {$[56]$} \\
\hline Aligned graphite electrodes & $\begin{array}{l}\text { Magnetic field assisted } \\
\text { casting }\end{array}$ & $\begin{array}{l}\sim 380 \mathrm{mAh} \mathrm{g}^{-1} \\
(0.1 \mathrm{C})\end{array}$ & - & $\sim 200 \mathrm{mAh} \mathrm{g}^{-1}(1 \mathrm{C})$ & {$[62]$} \\
\hline 3D BNG & $\mathrm{SiO}_{2}$ template-assisted-CVD & $\begin{array}{l}725 \mathrm{mAh} \mathrm{g}^{-1} \\
\left(1.5 \mathrm{~A} \mathrm{~g}^{-1}\right)\end{array}$ & 200 & $51 \mathrm{mAh} \mathrm{g}^{-1}(2.09 \mathrm{C})$ & {$[65]$} \\
\hline $\begin{array}{l}\mathrm{GO} / \mathrm{Sn}_{2} \mathrm{Fe}-\mathrm{NRs} \\
\text { array/rGO }\end{array}$ & Hydrothermal & $\begin{array}{l}90 \mathrm{mAh} \mathrm{g}^{-1} \\
\left(0.5 \mathrm{~A} \mathrm{~g}^{-1}\right)\end{array}$ & 600 & $682.5 \mathrm{mAh} \mathrm{g}^{-1}\left(2 \mathrm{~A} \mathrm{~g}^{-1}\right)$ & {$[80]$} \\
\hline $\mathrm{MoS}_{2} @ \mathrm{G}$ & Electrospinning and CVD & $\begin{array}{l}1150 \mathrm{mAh} \mathrm{g}^{-1} \\
\left(0.5 \mathrm{~A} \mathrm{~g}^{-1}\right)\end{array}$ & 160 & $700 \mathrm{mAh} \mathrm{g}^{-1}\left(10 \mathrm{~A} \mathrm{~g}^{-1}\right)$ & [87] \\
\hline $\mathrm{Gr}-\mathrm{Si}$ & CVD included $\mathrm{CO}_{2}$ oxidant & $\begin{array}{l}700 \mathrm{Wh} \mathrm{L}^{-1} \\
\left(3.0 \mathrm{mAh} \mathrm{cm}^{-2}\right)\end{array}$ & 200 & $2.7 \mathrm{mAh} \mathrm{cm}^{-2}(10 \mathrm{C})$ & [88] \\
\hline $\mathrm{MoS}_{2} / \mathrm{VGNS}$ & CVD and solvothermal & $\begin{array}{l}1109 \mathrm{mAh} \mathrm{g}^{-1} \\
\left(0.2 \mathrm{~A} \mathrm{~g}^{-1}\right)\end{array}$ & 100 & $\begin{array}{l}818 \mathrm{mAh} \mathrm{g}^{-1} \\
\left(2 \mathrm{~A} \mathrm{~g}^{-1}\right)\end{array}$ & [92] \\
\hline $\mathrm{RGO} / \mathrm{TiO}_{2}(\mathrm{~B})$ films & Grade layer-by-layer coating & $\begin{array}{l}128 \mathrm{mAh} \mathrm{g}^{-1} \\
\left(6.7 \mathrm{~A} \mathrm{~g}^{-1}\right)\end{array}$ & $\sim 5000$ & $\begin{array}{l}74 \mathrm{mAh} \mathrm{g}^{-1} \\
(20 \mathrm{C})\end{array}$ & [93] \\
\hline $\mathrm{Nb}_{2} \mathrm{O}_{5} / \mathrm{HGF}$ & $\begin{array}{l}\text { Self-assembly and } \mathrm{H}_{2} \mathrm{O}_{2} \\
\text { etching }\end{array}$ & $\begin{array}{l}\sim 190 \mathrm{mAh} \mathrm{g}^{-1} \\
\left(0.2 \mathrm{~A} \mathrm{~g}^{-1}\right)\end{array}$ & - & $\sim 80 \mathrm{mAh} \mathrm{g}^{-1}\left(20 \mathrm{~A} \mathrm{~g}^{-1}\right)$ & [97] \\
\hline $\mathrm{Si} / \mathrm{C}$ microspheres & Ball milling, spray drying & $\begin{array}{l}620 \mathrm{mAh} \mathrm{g}^{-1} \\
(0.1 \mathrm{C})\end{array}$ & 500 & $\sim 500 \mathrm{~mA} \mathrm{~h} \mathrm{~g}^{-1}(5 \mathrm{C})$ & [98] \\
\hline Yolk Sn@C nanobox & Solvothermal and annealing & $\begin{array}{l}810 \mathrm{mAh} \mathrm{g}^{-1} \\
\left(0.2 \mathrm{~A} \mathrm{~g}^{-1}\right)\end{array}$ & 500 & $350 \mathrm{~mA} \mathrm{~h} \mathrm{~g}^{-1}\left(4 \mathrm{~A} \mathrm{~g}^{-1}\right)$ & [101] \\
\hline $\begin{array}{l}\text { Graphene-encapsulated } \\
\text { SiMP }\end{array}$ & $\begin{array}{l}\text { Sacrificial Ni conformal } \\
\text { coating and CVD }\end{array}$ & $\begin{array}{l}1400 \mathrm{mAh} \mathrm{g}^{-1} \\
\left(1.5 \mathrm{~mA} \mathrm{~cm}^{-2}\right)\end{array}$ & 300 & - & [102] \\
\hline Ge-QD@NG/NGF & Ni template-assisted CVD & $\begin{array}{l}1220 \mathrm{mAh} \mathrm{g}^{-1} \\
\text { (1C) }\end{array}$ & 1000 & $801 \mathrm{mAh} \mathrm{g}^{-1}(40 \mathrm{C})$ & [104] \\
\hline GF/Si binder-free electrode & Freeze-drying & $\begin{array}{l}1170 \mathrm{mAh} \mathrm{g}^{-1} \\
\left(1 \mathrm{Ag}^{-1}\right)\end{array}$ & 1200 & $609 \mathrm{mAh} \mathrm{g}^{-1}\left(8 \mathrm{~A} \mathrm{~g}^{-1}\right)$ & [105] \\
\hline $\begin{array}{l}\mathrm{LiFePO}_{4} @ \mathrm{C} / \mathrm{rGO} \text { micro- } \\
\text { spheres }\end{array}$ & One-pot mixed-solvothermal & $\begin{array}{l}112.4 \mathrm{mAh} \mathrm{cm}^{-3} \\
(2 \mathrm{C})\end{array}$ & 700 & $109.3 \mathrm{mAh} \mathrm{g}^{-1}(10 \mathrm{C})$ & [109] \\
\hline $\mathrm{SnO}_{2} @ \mathrm{GC}$ & $\begin{array}{l}\text { Sulfur-templated capillary } \\
\text { shrinkage }\end{array}$ & $\begin{array}{l}974 \mathrm{mAh} \mathrm{g}^{-1 /} \\
2123 \mathrm{mAh} \mathrm{cm}^{-3} \\
\left(0.1 \mathrm{~A} \mathrm{~g}^{-1}\right)\end{array}$ & 300 & $\begin{array}{l}476 \mathrm{mAh} \mathrm{g}^{-1} \\
\left(2 \mathrm{~A} \mathrm{~g}^{-1}\right)\end{array}$ & [113] \\
\hline $\begin{array}{l}\text { 3D multi-channeled carbon- } \\
\text { based current collector }\end{array}$ & Carbonization and activation & $\begin{array}{l}3.8 \mathrm{mAh} \mathrm{cm}^{-2} \\
\left(2 \mathrm{~mA} \mathrm{~cm}^{-2}\right)\end{array}$ & 140 & $\begin{array}{l}1.7 \mathrm{mAh} \mathrm{cm}^{-2} \\
\left(20 \mathrm{~mA} \mathrm{~cm}^{-2}\right)\end{array}$ & {$[121]$} \\
\hline
\end{tabular}

conductivities, sluggish ion kinetics, and large volume expansions in electrodes, yielding excellent cycling and rate performance (Table 1). For the carbonaceous active material, especially the conventional graphite anode, decreasing tortuosity in a directional assembly strategy to enhance the rate performance of a thick anode is highly effective. For the carbon framework design, a variety of effective carbon models in terms of interface, network, void space, and density have been well developed to solve structural and interfacial instabilities and enhance charge kinetics under practical levels of pressing density, mass loading, and discharging/charging rates in high-capacity 
noncarbon electrodes. Besides, strengthened interfacial interactions and well-designed ion diffusion pathways in carbon current collectors not only reduce the proportion of inactive materials in the whole device, but also enhance the energy and power densities of LIBs.

Although existing carbon engineering can promote lithium-ion-storage performance, various issues still remain in terms of practical applications, such as their high-costs, low coulombic efficiencies, and limited volumetric energy densities, especially for high-capacity and high-volume-change noncarbon anodes, which need to be solved in future lithium-ion-battery research. To achieve commercial production, the development of advanced carbon-based-material assembly strategies that involve inexpensive and simple process, including one-step methods, but are also highly efficient and easy to translate to industrial production, is extremely urgent. Promisingly, the design of carbon cages is potentially useful for application to high-capacity noncarbon anodes. As the most typical noncarbon anode material, the $\mathrm{Si}$ anode, with an ultrahigh theoretical capacity of $3590 \mathrm{mAh} \mathrm{g}^{-1}$, is at the advent of industrialization, but it suffers from the main challenge of huge volume expansion (above 300\%) that leads to the continual loss of active material and the repetitive consumption of lithium resources (electrolyte and cathode). When the seriously unstable $\mathrm{Si}$ occupies a substantial portion of the electrode volume, carbon cages should be mechanically strengthened to house the volume-expanded silicon particles and block the intact electrolyte in order to protect the exposed surface during repeated lithiation. To simultaneously realize high volumetric performance and limited electrode expansion of the $\mathrm{Si}$ anode during battery charging, the carbon cages should be precisely designed to afford conformal compact protection with a trace amount. Therefore, the precise design of carbon cages for highcapacity noncarbon anodes is of great importance not only from the perspective of fundamental design studies into high volumetric materials, but also for promoting highcapacity noncarbon anodes based on nanocarbons into real electrochemical energy-storage devices.

Acknowledgements This work is supported by the National Science Fund for Distinguished Young Scholars of China (No. 51525204), National Key Basic Research Program of China (2014CB932400) and the National Natural Science Foundation of China (No. 51872195 and U1401243).
Open Access This article is distributed under the terms of the Creative Commons Attribution 4.0 International License (http:// creativecommons.org/licenses/by/4.0/), which permits unrestricted use, distribution, and reproduction in any medium, provided you give appropriate credit to the original author(s) and the source, provide a link to the Creative Commons license, and indicate if changes were made.

\section{References}

1. J.M. Tarascon, M. Armand, Issues and challenges facing rechargeable lithium batteries. Nature 414(6861), 359-367 (2001). https://doi.org/10.1038/35104644

2. M. Armand, J.M. Tarascon, Building better batteries. Nature 451(7179), 652-657 (2008). https://doi. org/10.1038/451652a

3. S. Chu, A. Majumdar, Opportunities and challenges for a sustainable energy future. Nature 488(7411), 294-303 (2012). https://doi.org/10.1038/nature11475

4. D. Larcher, J.M. Tarascon, Towards greener and more sustainable batteries for electrical energy storage. Nat. Chem. 7(1), 19-29 (2015). https://doi.org/10.1038/nchem.2085

5. M.R. Lukatskaya, B. Dunn, Y. Gogotsi, Multidimensional materials and device architectures for future hybrid energy storage. Nat. Commun. 7, 12647 (2016). https://doi. org/10.1038/ncomms 12647

6. V. Etacheri, R. Marom, R. Elazari, G. Salitra, D. Aurbach, Challenges in the development of advanced Li-ion batteries: a review. Energy Environ. Sci. 4(9), 3243-3262 (2011). https://doi.org/10.1039/c1ee01598b

7. K. Kang, Y.S. Meng, J. Bg, C.P. Grey, G. Ceder, Electrodes with high power and high capacity for rechargeable lithium batteries. Science 311(5763), 977-980 (2006). https://doi. org/10.1126/science.1122152

8. J.W. Choi, D. Aurbach, Promise and reality of post-lithiumion batteries with high energy densities. Nat. Rev. Mater. 1(4), 16013 (2016). https://doi.org/10.1038/natrevmats .2016 .13

9. J.B. Goodenough, Electrochemical energy storage in a sustainable modern society. Energy Environ. Sci. 7(1), 14-18 (2014). https://doi.org/10.1039/C3EE42613K

10. S.A. Freunberger, True performance metrics in beyondintercalation batteries. Nat. Energy 2, 17091 (2017). https ://doi.org/10.1038/nenergy.2017.91

11. J. Zhang, Y. Bai, X.G. Sun, Y. Li, B. Guo et al., Superior conductive solid-like electrolytes: nanoconfining liquids within the hollow structures. Nano Lett. 15(5), 3398-3402 (2015). https://doi.org/10.1021/acs.nanolett.5b00739

12. J. Luo, J. Liu, Z. Zeng, C.F. Ng, L. Ma, H. Zhang, J. Lin, Z. Shen, H.J. Fan, Three-dimensional graphene foam supported $\mathrm{Fe}_{3} \mathrm{O}_{4}$ lithium battery anodes with long cycle life and high rate capability. Nano Lett. 13(12), 6136-6143 (2013). https://doi.org/10.1021/nl403461n 
13. N. Mahmood, Y. Hou, Electrode nanostructures in lithiumbased batteries. Adv. Sci. 1(1), 1400012 (2014). https://doi. org/10.1002/advs.201400012

14. W. Lv, Z. Li, Y. Deng, Q.H. Yang, F. Kang, Graphenebased materials for electrochemical energy storage devices: opportunities and challenges. Energy Storage Mater. 2, 107-138 (2016). https://doi.org/10.1016/j. ensm.2015.10.002

15. C. Zhang, W. Lv, Y. Tao, Q.H. Yang, Towards superior volumetric performance: design and preparation of novel carbon materials for energy storage. Energy Environ. Sci. 8(5), 1390-1403 (2015). https://doi.org/10.1039/C5EE00389J

16. M.J. Lee, E. Lho, P. Bai, S. Chae, J. Li, J. Cho, Low-temperature carbon coating of nanosized $\mathrm{Li}_{1.015} \mathrm{Al}_{0.06} \mathrm{Mn}_{1.925} \mathrm{O}_{4}$ and high-density electrode for high-power Li-ion batteries. Nano Lett. 17(6), 3744-3751 (2017). https://doi.org/10.1021/acs. nanolett.7b01076

17. Y.M. Chen, X.Y. Yu, Z. Li, U. Paik, X.W. Lou, Hierarchical $\mathrm{MoS}_{2}$ tubular structures internally wired by carbon nanotubes as a highly stable anode material for lithium-ion batteries. Sci. Adv. 2(7), e1600021 (2016). https://doi.org/10.1126/ sciadv. 1600021

18. G. Huang, F. Zhang, X. Du, Y. Qin, D. Yin, L. Wang, Metal organic frameworks route to in situ insertion of multiwalled carbon nanotubes in $\mathrm{Co}_{3} \mathrm{O}_{4}$ polyhedra as anode materials for lithium-ion batteries. ACS Nano 9(2), 1592-1599 (2015). https://doi.org/10.1021/nn506252u

19. H. Xia, Q. Xu, J. Zhang, Recent progress on two-dimensional nanoflake ensembles for energy storage applications. NanoMicro Lett. 10, 66 (2018). https://doi.org/10.1007/s4082 0-018-0219-z

20. M.F. El-Kady, Y. Shao, R.B. Kaner, Graphene for batteries, supercapacitors and beyond. Nat. Rev. Mater. 1, 16033 (2016). https://doi.org/10.1038/natrevmats.2016.33

21. R. Fang, K. Chen, L. Yin, Z. Sun, F. Li, H.M. Cheng, The regulating role of carbon nanotubes and graphene in lithiumion and lithium-sulfur batteries. Adv. Mater. (2018). https:// doi.org/10.1002/adma.201800863

22. Z. Li, S. Wu, W. Lv, J.J. Shao, F. Kang, Q.H. Yang, Graphene emerges as a versatile template for materials preparation. Small 12(20), 2674-2688 (2016). https://doi.org/10.1002/ smll.201503722

23. Y. Zhao, L.P. Wang, M.T. Sougrati, Z.X. Feng, Y. Leconte, A. Fisher, M. Srinivasan, Z.C. Xu, A review on design strategies for carbon based metal oxides and sulfides nanocomposites for high performance Li and $\mathrm{Na}$ ion battery anodes. Adv. Energy Mater. 7(9), 1601424 (2017). https://doi.org/10.1002/ aenm.201601424

24. W. Li, L. Zeng, Y. Wu, Y. Yu, Nanostructured electrode materials for lithium-ion and sodium-ion batteries via electrospinning. Sci. China Mater. 59(4), 287-321 (2016). https://doi. org/10.1007/s40843-016-5039-6

25. Z. Chen, W. Ren, L. Gao, B. Liu, S. Pei, H.M. Cheng, Threedimensional flexible and conductive interconnected graphene networks grown by chemical vapour deposition. Nat. Mater. 10(6), 424-428 (2011). https://doi.org/10.1038/nmat3001
26. J.-J. Shao, W. Lv, Q.H. Yang, Self-assembly of graphene oxide at interfaces. Adv. Mater. 26(32), 5586-5612 (2014). https://doi.org/10.1002/adma.201400267

27. L. Zhang, G. Zhang, H.B. Wu, L. Yu, X.W. Lou, Hierarchical tubular structures constructed by carbon-coated $\mathrm{SnO}_{2}$ nanoplates for highly reversible lithium storage. Adv. Mater. 25(18), 2589-2593 (2013). https://doi.org/10.1002/ adma.201300105

28. A.L.M. Reddy, M.M. Shaijumon, S.R. Gowda, P.M. Ajayan, Coaxial $\mathrm{MnO}_{2}$ /carbon nanotube array electrodes for highperformance lithium batteries. Nano Lett. 9(3), 1002-1006 (2009). https://doi.org/10.1021/nl803081j

29. N. Liu, H. Wu, M.T. McDowell, Y. Yao, C. Wang, Y. Cui, A yolk-shell design for stabilized and scalable Li-ion battery alloy anodes. Nano Lett. 12(6), 3315-3321 (2012). https:// doi.org/10.1021/n13014814

30. N. Liu, Z. Lu, J. Zhao, M.T. McDowell, H.W. Lee, W. Zhao, Y. Cui, A pomegranate-inspired nanoscale design for largevolume-change lithium battery anodes. Nat. Nanotechnol. 9(3), 187-192 (2014). https://doi.org/10.1038/nnano.2014.6

31. Z. Li, J. Ding, H.L. Wang, K. Cui, T. Stephenson, D. Karpuzov, D. Mitlin, High rate $\mathrm{SnO}_{2}$-graphene dual aerogel anodes and their kinetics of lithiation and sodiation. Nano Energy 15, 369-378 (2015). https://doi.org/10.1016/j.nanoe n.2015.04.018

32. B. Wang, W. Li, T. Wu, J. Guo, Z. Wen, Self-template construction of mesoporous silicon submicrocube anode for advanced lithium ion batteries. Energy Storage Mater. 15, 139-147 (2018). https://doi.org/10.1016/j. ensm.2018.03.025

33. G.L. Xia, J.W. Su, M.S. Li, P. Jiang, Y. Yang, Q. Chen, A MOF-derived self-template strategy toward cobalt phosphide electrodes with ultralong cycle life and high capacity. J. Mater. Chem. A 5(21), 10321-10327 (2017). https://doi. org/10.1039/c7ta02600e

34. J. Yao, K. Zhang, W. Wang, X. Zuo, Q. Yang, H. Tang, M. $\mathrm{Wu}, \mathrm{G}$. Li, Functional integration and self-template synthesis of hollow core-shell carbon mesoporous spheres/ $/ \mathrm{Fe}_{3} \mathrm{O}_{4} /$ nitrogen-doped graphene to enhance catalytic activity in DSSCs. Nanoscale 10(17), 7946-7956 (2018). https://doi. org/10.1039/c8nr01095a

35. L. Dang, C. Wei, H. Ma, Q. Lu, F. Gao, Three-dimensional honeycomb-like networks of birnessite mang anese oxide assembled by ultrathin two-dimensional nanosheets with enhanced Li-ion battery performances. Nanoscale 7(17), 8101-8109 (2015). https://doi.org/10.1039/c5nr00576k

36. Z. Wan, J. Shao, J. Yun, H. Zheng, T. Gao, M. Shen, Q. Qu, H. Zheng, Core-shell structure of hierarchical quasi-hollow $\mathrm{MoS}_{2}$ microspheres encapsulated porous carbon as stable anode for Li-ion batteries. Small 10(23), 4975-4981 (2014). https://doi.org/10.1002/smll.201401286

37. L. Yu, H.B. Wu, X.W.D. Lou, Self-templated formation of hollow structures for electrochemical energy applications. Acc. Chem. Res. 50(2), 293-301 (2017). https://doi. org/10.1021/acs.accounts.6b00480 
38. L. Jabbour, M. Destro, C. Gerbaldi, D. Chaussy, N. Penazzi, D. Beneventi, Aqueous processing of cellulose based paperanodes for flexible Li-ion batteries. J. Mater. Chem. 22(7), 3227-3233 (2012). https://doi.org/10.1039/c2jm15117k

39. R. Wang, C. Xu, J. Sun, L. Gao, C. Lin, Flexible free-standing hollow $\mathrm{Fe}_{3} \mathrm{O}_{4}$ /graphene hybrid films for lithium-ion batteries. J. Mater. Chem. A 1(5), 1794-1800 (2013). https://doi. org/10.1039/c2ta00753c

40. Z. Wang, C. Xu, P. Tammela, J. Huo, M. Strømme, K. Edström, T. Gustafsson, L. Nyholm, Flexible freestanding Cladophora nanocellulose paper based Si anodes for lithiumion batteries. J. Mater. Chem. A 3(27), 14109-14115 (2015). https://doi.org/10.1039/c5ta02136g

41. R.V. Salvatierra, A.R.O. Raji, S.K. Lee, Y.S. Ji, L. Li, J.M. Tour, Silicon nanowires and lithium cobalt oxide nanowires in graphene nanoribbon papers for full lithium ion battery. Adv. Energy Mater. 6(24), 1600918 (2016). https://doi. org/10.1002/aenm.201600918

42. L. Gao, Y. Jin, X. Liu, M. Xu, X. Lai, J. Shui, A rationally assembled graphene nanoribbon/graphene framework for high volumetric energy and power density Li-ion batteries. Nanoscale 10(16), 7676-7684 (2018). https://doi. org/10.1039/c8nr00692j

43. Y. Ge, C. Wang, Y. Zhao, Y. Liu, Y. Chao, T. Zheng, G.G. Wallace, An electrosynthesized 3D porous molybdenum sulfide/graphene film with enhanced electrochemical performance for lithium storage. Small 14(9), 1703096 (2018). https://doi.org/10.1002/smll.201703096

44. Y. Yang, J. Huang, J. Zeng, J. Xiong, J. Zhao, Direct electrophoretic deposition of binder-free $\mathrm{Co}_{3} \mathrm{O}_{4}$ /graphene sandwichlike hybrid electrode as remarkable lithium ion battery anode. ACS Appl. Mater. Interfaces. 9(38), 32801-32811 (2017). https://doi.org/10.1021/acsami.7b10683

45. C. Niu, J. Meng, X. Wang, C. Han, M. Yan et al., General synthesis of complex nanotubes by gradient electrospinning and controlled pyrolysis. Nat. Commun. 6, 7402 (2015). https ://doi.org/10.1038/ncomms8402

46. M. Wang, L. He, Y. Yin, Magnetic field guided colloidal assembly. Mater. Today 16(4), 110-116 (2013). https://doi. org/10.1016/j.mattod.2013.04.008

47. D. Toulemon, M.V. Rastei, D. Schmool, J.S. Garitaonandia, L. Lezama, X. Cattoen, S. Begin-Colin, B.P. Pichon, Enhanced collective magnetic properties induced by the controlled assembly of iron oxide nanoparticles in chains. Adv. Funct. Mater. 26(15), 2454-2462 (2016). https://doi. org/10.1002/adfm.201505086

48. R. Du, Q. Zhao, Z. Zheng, W. Hu, J. Zhang, 3D self-supporting porous magnetic assemblies for water remediation and beyond. Adv. Energy Mater. 6(17), 1600473 (2016). https:// doi.org/10.1002/aenm.201600473

49. F. Xu, C.-a.M. Wu, V. Rengarajan, T.D. Finley, H.O. Keles, Y.R. Sung, B. Li, U.A. Gurkan, U. Demirci, Three-dimensional magnetic assembly of microscale hydrogels. Adv. Mater. 23(37), 4254-4260 (2011). https://doi.org/10.1002/ adma.201101962
50. R.M. Erb, R. Libanori, N. Rothfuchs, A.R. Studart, Composites reinforced in three dimensions by using low magnetic fields. Science 335(6065), 199-204 (2012). https://doi. org/10.1126/science. 1210822

51. H.L. Ferrand, S. Bolisetty, A.F. Demirors, R. Libanori, A.R. Studart, R. Mezzenga, Magnetic assembly of transparent and conducting graphene-based functional composites. Nat. Commun. 7, 12078 (2016). https://doi.org/10.1038/ncomms 1207 8

52. K. Zhang, W. Zhao, J.T. Lee, G. Jang, X. Shi, J.H. Park, A magnetic field assisted self-assembly strategy towards strongly coupled $\mathrm{Fe}_{3} \mathrm{O}_{4}$ nanocrystal/rGO paper for highperformance lithium ion batteries. J. Mater. Chem. A 2(25), 9636-9644 (2014). https://doi.org/10.1039/c4ta00821a

53. M. Kawamori, T. Asai, Y. Shirai, S. Yagi, M. Oishi, T. Ichitsubo, E. Matsubara, Three-dimensional nanoelectrode by metal nanowire nonwoven clothes. Nano Lett. 14(4), 19321937 (2014). https://doi.org/10.1021/nl404753e

54. J. Qin, Q. Zhang, Z. Cao, X. Li, C. Hu, B. Wei, MnOxSWCNT macro-films as flexible binder-free anodes for highperformance Li-ion batteries. Nano Energy 2(5), 733-741 (2013). https://doi.org/10.1016/j.nanoen.2012.12.009

55. Q. Zhang, S. Tan, R.G. Mendes, Z. Sun, Y. Chen et al., Extremely weak van der waals coupling in vertical $\mathrm{ReS}_{2}$ nanowalls for high-current-density lithium-ion batteries. Adv. Mater. 28(13), 2616-2623 (2016). https://doi.org/10.1002/ adma.201505498

56. A. Gohier, B. Laik, K.H. Kim, J.L. Maurice, J.P. PereiraRamos, C.S. Cojocaru, P.T. Van, High-rate capability silicon decorated vertically aligned carbon nanotubes for Liion batteries. Adv. Mater. 24(19), 2592-2597 (2012). https ://doi.org/10.1002/adma.201104923

57. S. Huang, L.Z. Cheong, D. Wang, C. Shen, Nanostructured phosphorus doped silicon/graphite composite as anode for high-performance lithium-ion batteries. ACS Appl. Mater. Interfaces. 9(28), 23672-23678 (2017). https://doi. org/10.1021/acsami.7b04361

58. G. Tan, R. Xu, Z. Xing, Y. Yuan, J. Lu et al., Burning lithium in $\mathrm{CS}_{2}$ for high-performing compact $\mathrm{Li}_{2} \mathrm{~S}$-graphene nanocapsules for Li-S batteries. Nat. Energy 2, 17090 (2017). https://doi.org/10.1038/nenergy.2017.90

59. L. Wen, F. Li, H.M. Cheng, Carbon nanotubes and graphene for flexible electrochemical energy storage: from materials to devices. Adv. Mater. 28(22), 4306-4337 (2016). https:// doi.org/10.1002/adma.201504225

60. A.D. Roberts, X. Li, H.F. Zhang, Porous carbon spheres and monoliths: morphology control, pore size tuning and their applications as Li-ion battery anode materials. Chem. Soc. Rev. 43(13), 4341-4356 (2014). https://doi.org/10.1039/ c4cs00071d

61. K.N. Wood, R. O'Hayre, S. Pylypenko, Recent progress on nitrogen/carbon structures designed for use in energy and sustainability applications. Energy Environ. Sci. 7(4), 1212-1249 (2014). https://doi.org/10.1039/c3ee44078h

62. J. Billaud, F. Bouville, T. Magrini, C. Villevieille, A.R. Studart, Magnetically aligned graphite electrodes for 
high-rate performance Li-ion batteries. Nat. Energy 1, 16097 (2016). https://doi.org/10.1038/nenergy.2016.97

63. C. Li, G. Shi, Functional gels based on chemically modified graphenes. Adv. Mater. 26(24), 3992-4012 (2014). https:// doi.org/10.1002/adma.201306104

64. X. Wang, L. Lv, Z. Cheng, J. Gao, L. Dong, C. Hu, L. $\mathrm{Qu}$, High-density monolith of N-doped holey graphene for ultrahigh volumetric capacity of Li-ion batteries. Adv. Energy Mater. 6(6), 1502100 (2016). https://doi. org/10.1002/aenm.201502100

65. J. Dong, Y. Xue, C. Zhang, Q. Weng, P. Dai et al., Improved $\mathrm{Li}^{+}$storage through homogeneous $\mathrm{N}$-doping within highly branched tubular graphitic foam. Adv. Mater. 29(6), 1603692 (2017). https://doi.org/10.1002/adma.201603692

66. U. Kasavajjula, C. Wang, A.J. Appleby, Nano- and bulksilicon-based insertion anodes for lithium-ion secondary cells. J. Power Sources 163(2), 1003-1039 (2007). https:// doi.org/10.1016/j.jpowsour.2006.09.084

67. B. Wang, B. Luo, X. Li, L. Zhi, The dimensionality of Sn anodes in Li-ion batteries. Mater. Today 15(12), 544-552 (2012). https://doi.org/10.1016/S1369-7021(13)70012-9

68. C.K. Chan, X.F. Zhang, Y. Cui, High capacity Li ion battery anodes using Ge nanowires. Nano Lett. 8(1), 307-309 (2008). https://doi.org/10.1021/n10727157

69. Y. Li, B. Tan, Y. Wu, Mesoporous $\mathrm{Co}_{3} \mathrm{O}_{4}$ nanowire arrays for lithium ion batteries with high capacity and rate capability. Nano Lett. 8(1), 265-270 (2008). https://doi. org/10.1021/n10725906

70. G. Zhou, D.W. Wang, F. Li, L. Zhang, N. Li, Z.S. Wu, L. Wen, G.Q. Lu, H.-M. Cheng, Graphene-wrapped $\mathrm{Fe}_{3} \mathrm{O}_{4}$ anode material with improved reversible capacity and cyclic stability for lithium ion batteries. Chem. Mater. 22(18), 5306-5313 (2010). https://doi.org/10.1021/cm101 $532 \mathrm{x}$

71. S.M. Paek, E. Yoo, I. Honma, Enhanced cyclic performance and lithium storage capacity of $\mathrm{SnO}_{2}$ /graphene nanoporous electrodes with three-dimensionally delaminated flexible structure. Nano Lett. 9(1), 72-75 (2009). https://doi. org/10.1021/n1802484w

72. M.V. Reddy, G.V. Subba Rao, B.V.R. Chowdari, Metal oxides and oxysalts as anode materials for Li ion batteries. Chem. Rev. 113(7), 5364-5457 (2013). https://doi.org/10.1021/ cr3001884

73. K. Chang, W. Chen, L-cysteine-assisted synthesis of layered $\mathrm{MoS}_{2}$ /graphene composites with excellent electrochemical performances for lithium ion batteries. ACS Nano 5(6), 4720-4728 (2011). https://doi.org/10.1021/nn200659w

74. R. Bhandavat, L. David, G. Singh, Synthesis of surface-functionalized $\mathrm{WS}_{2}$ nanosheets and performance as Li-ion battery anodes. J. Phys. Chem. Lett. 3(11), 1523-1530 (2012). https ://doi.org/10.1021/jz300480w

75. Y.M. Zhao, Y.P. Cui, J. Shi, W. Liu, Z.C. Shi, S.G. Chen, X. Wang, H.L. Wang, Two-dimensional biomass-derived carbon nanosheets and $\mathrm{MnO} /$ carbon electrodes for high-performance Li-ion capacitors. J. Mater. Chem. A 5(29), 15243-15252 (2017). https://doi.org/10.1039/C7TA04154C
76. J. Han, W. Wei, C. Zhang, Y. Tao, W. Lv, G. Ling, F. Kang, Q.H. Yang, Engineering graphenes from the nano- to the macroscale for electrochemical energy storage. Electrochem. Energ. Rev. 1(2), 139-168 (2018). https://doi.org/10.1007/ s41918-018-0006-z

77. X. Li, L. Zhi, Graphene hybridization for energy storage applications. Chem. Soc. Rev. 47(9), 3189-3216 (2018). https ://doi.org/10.1039/C7CS00871F

78. T.R. Tang, Q. Yun, W. Lv, Y.B. He, C. You, F. Su, L. Ke, B. Li, F. Kang, Q.H. Yang, How a very trace amount of graphene additive works for constructing an efficient conductive network in $\mathrm{LiCoO}_{2}$-based lithium-ion batteries. Carbon 103, 356-362 (2016). https://doi.org/10.1016/j.carbo n.2016.03.032

79. Y. Zhang, W. Bai, J. Ren, W. Weng, H. Lin, Z. Zhang, H. Peng, Super-stretchy lithium-ion battery based on carbon nanotube fiber. J. Mater. Chem. A 2(29), 11054-11059 (2014). https://doi.org/10.1039/c4ta01878h

80. C. Wang, J. Wang, H. Chen, M. Wen, K. Xing, S. Chen, Q. $\mathrm{Wu}, \mathrm{An}$ interlayer nanostructure of $\mathrm{rGO} / \mathrm{Sn}_{2} \mathrm{Fe}-\mathrm{NRs}$ array/ rGO with high capacity for lithium ion battery anodes. Sci. China Mater. 59(11), 927-937 (2016). https://doi. org/10.1007/s40843-016-5086-7

81. J. Zhu, Q. Wu, J. Key, M. Wu, P.K. Shen, Self-assembled superstructure of carbon-wrapped, single-crystalline $\mathrm{Cu}_{3} \mathrm{P}$ porous nanosheets: one-step synthesis and enhanced $\mathrm{Li}$-ion battery anode performance. Energy Storage Mater. 15, 75-81 (2018). https://doi.org/10.1016/j.ensm.2018.03.014

82. H. He, D. Kong, B. Wang, W. Fu, X. Qiu, Q.H. Yang, L. Zhi, Carbon-network-integrated $\mathrm{SnSiO}_{\mathrm{x}+2}$ Nanofiber sheathed by ultrathin graphitic carbon for highly reversible lithium storage. Adv. Energy Mater. 6(10), 1502495 (2016). https://doi. org/10.1002/aenm.201502495

83. F.Y. Su, C. You, Y.B. He, W. Lv, W. Cui, F. Jin, B. Li, Q.H. Yang, F. Kang, Flexible and planar graphene conductive additives for lithium-ion batteries. J. Mater. Chem. 20(43), 9644-9650 (2010). https://doi.org/10.1039/C0JM01633K

84. F.Y. Su, Y.B. He, B. Li, X.-C. Chen, C.H. You, W. Wei, W. Lv, Q.H. Yang, F. Kang, Could graphene construct an effective conducting network in a high-power lithium ion battery? Nano Energy 1(3), 429-439 (2012). https://doi.org/10.1016/j. nanoen.2012.02.004

85. J. Ryu, T. Chen, T. Bok, G. Song, J. Ma et al., Mechanical mismatch-driven rippling in carbon-coated silicon sheets for stress-resilient battery anodes. Nat. Commun. 9(1), 2924 (2018). https://doi.org/10.1038/s41467-018-05398-9

86. S. Jing, H. Jiang, Y. Hu, J. Shen, C. Li, Face-to-face contact and open-void coinvolved $\mathrm{Si} / \mathrm{C}$ nanohybrids lithium-ion battery anodes with extremely long cycle life. Adv. Funct. Mater. 25(33), 5395-5401 (2015). https://doi.org/10.1002/ adfm. 201502330

87. D. Kong, H. He, Q. Song, B. Wang, W. Lv, Q.H. Yang, L. Zhi, Rational design of $\mathrm{MoS}_{2} @$ graphene nanocables: towards high performance electrode materials for lithium ion batteries. Energy Environ. Sci. 7(10), 3320-3325 (2014). https:// doi.org/10.1039/c4ee02211d 
88. I.H. Son, J.H. Park, S. Kwon, S. Park, M.H. Rümmeli et al., Silicon carbide-free graphene growth on silicon for lithiumion battery with high volumetric energy density. Nat. Commun. 6, 7393 (2015). https://doi.org/10.1038/ncomms8393

89. N. Li, S. Jin, Q. Liao, H. Cui, C.X. Wang, Encapsulated within graphene shell silicon nanoparticles anchored on vertically aligned graphene trees as lithium ion battery anodes. Nano Energy 5, 105-115 (2014). https://doi.org/10.1016/j. nanoen.2014.02.011

90. S. Jin, N. Li, H. Cui, C. Wang, Growth of the vertically aligned graphene@ amorphous GeOx sandwich nanoflakes and excellent Li storage properties. Nano Energy 2(6), 11281136 (2013). https://doi.org/10.1016/j.nanoen.2013.09.008

91. N. Li, H. Song, H. Cui, C. Wang, Sn@graphene grown on vertically aligned graphene for high-capacity, high-rate, and long-life lithium storage. Nano Energy 3, 102-112 (2014). https://doi.org/10.1016/j.nanoen.2013.10.014

92. Y. Wang, B. Chen, D.H. Seo, Z.J. Han, J.I. Wong, K. Ostrikov, H. Zhang, H.Y. Yang, $\mathrm{MoS}_{2}$-coated vertical graphene nanosheet for high-performance rechargeable lithiumion batteries and hydrogen production. NPG Asia Mater. 8, e268 (2016). https://doi.org/10.1038/am.2016.44

93. Y. Zhang, O.I. Malyi, Y. Tang, J. Wei, Z. Zhu et al., Reducing the charge carrier transport barrier in functionally layergraded electrodes. Angew. Chem. Int. Ed. 56(47), 1484714852 (2017). https://doi.org/10.1002/anie.201707883

94. L. Shen, Q. Che, H. Li, X. Zhang, Mesoporous $\mathrm{NiCo}_{2} \mathrm{O}_{4}$ nanowire arrays grown on carbon textiles as binder-free flexible electrodes for energy storage. Adv. Funct. Mater. 24(18), 2630-2637 (2014). https://doi.org/10.1002/adfm.201303138

95. G. Wang, J. Zhang, S. Yang, F. Wang, X. Zhuang, K. Müllen, X. Feng, Vertically aligned $\mathrm{MoS}_{2}$ nanosheets patterned on electrochemically exfoliated graphene for high-performance lithium and sodium storage. Adv. Energy Mater. 8(8), 1702254 (2018). https://doi.org/10.1002/aenm.201702254

96. H. Wang, Z. Xu, Z. Li, K. Cui, J. Ding et al., Hybrid device employing three-dimensional arrays of $\mathrm{MnO}$ in carbon nanosheets bridges battery-supercapacitor divide. Nano Lett. 14(4), 1987-1994 (2014). https://doi.org/10.1021/nl500011d

97. H. Sun, L. Mei, J. Liang, Z. Zhao, C. Lee et al., Three-dimensional holey-graphene/niobia composite architectures for ultrahigh-rate energy storage. Science 356(6338), 599-604 (2017). https://doi.org/10.1126/science.aam5852

98. Q. Xu, J.Y. Li, J.K. Sun, Y.X. Yin, L.J. Wan, Y.G. Guo, Watermelon-inspired $\mathrm{Si} / \mathrm{C}$ microspheres with hierarchical buffer structures for densely compacted lithium-ion battery anodes. Adv. Energy Mater. 7(3), 1601481 (2017). https:// doi.org/10.1002/aenm.201601481

99. X.Y. Yu, L. Yu, L. Shen, X. Song, H. Chen, X.W. Lou, General formation of MS ( $\mathrm{M}=\mathrm{Ni}, \mathrm{Cu}, \mathrm{Mn})$ box-in-box hollow structures with enhanced pseudocapacitive properties. Adv. Funct. Mater. 24(47), 7440-7446 (2014). https://doi. org/10.1002/adfm.201402560

100. J. Zhang, K. Wang, Q. Xu, Y. Zhou, F. Cheng, S. Guo, Beyond yolk shell nanoparticles $\mathrm{Fe}_{3} \mathrm{O}_{4} @ \mathrm{Fe}_{3} \mathrm{C} @$ core shell nanoparticles as yolks and carbon nanospindles as shells for efficient lithium ion storage. ACS Nano 9(3), 3369-3376 (2015). https://doi.org/10.1021/acsnano.5b00760

101. H. Zhang, X. Huang, O. Noonan, L. Zhou, C. Yu, Tailored yolk-shell Sn@C nanoboxes for high-performance lithium storage. Adv. Funct. Mater. 27(8), 1606023 (2017). https:// doi.org/10.1002/adfm.201606023

102. Y. Li, K. Yan, H.W. Lee, Z. Lu, N. Liu, Y. Cui, Growth of conformal graphene cages on micrometre-sized silicon particles as stable battery anodes. Nat. Energy 1, 15029 (2016). https://doi.org/10.1038/nenergy.2015.29

103. D.S. Jung, T.H. Hwang, S.B. Park, J.W. Choi, Spray drying method for large-scale and high-performance silicon negative electrodes in Li-ion batteries. Nano Lett. 13(5), 2092-2097 (2013). https://doi.org/10.1021/nl400437f

104. R. Mo, D. Rooney, K. Sun, H.Y. Yang, 3D nitrogen-doped graphene foam with encapsulated germanium/nitrogen-doped graphene yolk-shell nanoarchitecture for high-performance flexible Li-ion battery. Nat. Commun. 8, 13949 (2017). https ://doi.org/10.1038/ncomms13949

105. Y. Ma, R. Younesi, R. Pan, C. Liu, J. Zhu, B. Wei, K. Edström, Constraining Si particles within graphene foam monolith: interfacial modification for high-performance $\mathrm{Li}^{+}$ storage and flexible integrated configuration. Adv. Funct. Mater. 26(37), 6797-6806 (2016). https://doi.org/10.1002/ adfm.201602324

106. K.J. Griffith, K.M. Wiaderek, G. Cibin, L.E. Marbella, C.P. Grey, Niobium tungsten oxides for high-rate lithium-ion energy storage. Nature 559(7715), 556-563 (2018). https:// doi.org/10.1038/s41586-018-0347-0

107. Y. Lu, L. Yu, X.W. Lou, Nanostructured conversion-type anode materials for advanced lithium-ion batteries. Chem 4(5), 972-996 (2018). https://doi.org/10.1016/j.chemp r.2018.01.003

108. Z. Li, D. Kong, G. Zhou, S. Wu, W. Lv et al., Twin-functional graphene oxide: compacting with $\mathrm{Fe}_{2} \mathrm{O}_{3}$ into a high volumetric capacity anode for lithium ion battery. Energy Storage Mater. 6, 98-103 (2017). https://doi.org/10.1016/j. ensm.2016.09.005

109. H. Wang, L. Liu, R. Wang, X. Yan, Z. Wang et al., Selfassembly of antisite defectless nano-LiFePO $@$ @ $/$ reduced graphene oxide microspheres for high-performance lithiumion batteries. Chemsuschem 11(13), 2255-2261 (2018). https ://doi.org/10.1002/cssc.201800786

110. H. Li, X. Wang, Three-dimensional architectures constructed using two-dimensional nanosheets. Sci. China Chem. 58(12), 1792-1799 (2015). https://doi.org/10.1007/s1142 6-015-5511-x

111. C. Zhang, D.H. Liu, W. Lv, D.W. Wang, W. Wei et al., A high-density graphene-sulfur assembly: a promising cathode for compact Li-S batteries. Nanoscale 7(13), 5592-5597 (2015). https://doi.org/10.1039/C4NR06863G

112. Y. Tao, X. Xie, W. Lv, D.M. Tang, D. Kong et al., Towards ultrahigh volumetric capacitance: graphene derived highly dense but porous carbons for supercapacitors. Sci. Rep. 3, 2975 (2013). https://doi.org/10.1038/srep02975 
113. J. Han, D. Kong, W. Lv, D.M. Tang, D. Han et al., Caging tin oxide in three-dimensional graphene networks for superior volumetric lithium storage. Nat. Commun. 9, 402 (2018). https://doi.org/10.1038/s41467-017-02808-2

114. J. Ni, Y. Li, Carbon nanomaterials in different dimensions for electrochemical energy storage. Adv. Energy Mater. 6(17), 1600278 (2016). https://doi.org/10.1002/aenm.201600278

115. Z. Wu, K. Liu, C. Lv, S. Zhong, Q. Wang et al., Ultrahighenergy density lithium-ion cable battery based on the carbonnanotube woven macrofilms. Small 14(22), 1800414 (2018). https://doi.org/10.1002/smll.201800414

116. L. Hu, H. Wu, Y. Gao, A. Cao, H. Li, J. McDough, X. Xie, M. Zhou, Y. Cui, Silicon-carbon nanotube coaxial sponge as Li-ion anodes with high areal capacity. Adv. Energy Mater. 1(4), 523-527 (2011). https://doi.org/10.1002/aenm.20110 0056

117. W. Wei, S. Yang, H. Zhou, I. Lieberwirth, X. Feng, K. Müllen, 3D graphene foams cross-linked with pre-encapsulated $\mathrm{Fe}_{3} \mathrm{O}_{4}$ nanospheres for enhanced lithium storage. Adv. Mater. 25(21), 2909-2914 (2013). https://doi.org/10.1002/ adma.201300445

118. D. Chao, X. Xia, J. Liu, Z. Fan, C.F. Ng, J. Lin, H. Zhang, Z.X. Shen, H.J. Fan, $\mathrm{A}_{2} \mathrm{O}_{5}$ /conductive-polymer core/shell nanobelt array on three-dimensional graphite foam: a highrate, ultrastable, and freestanding cathode for lithium-ion batteries. Adv. Mater. 26(33), 5794-5800 (2014). https://doi. org/10.1002/adma.201400719
119. J. Wang, J. Liu, D. Chao, J. Yan, J. Lin, Z.X. Shen, Selfassembly of honeycomb-like $\mathrm{MoS}_{2}$ nanoarchitectures anchored into graphene foam for enhanced lithium-ion storage. Adv. Mater. 26(42), 7162-7169 (2014). https://doi. org/10.1002/adma.201402728

120. M. Zhu, J. Song, T. Li, A. Gong, Y. Wang et al., Highly anisotropic, highly transparent wood composites. Adv. Mater. 28(26), 5181-5187 (2016). https://doi.org/10.1002/ adma.201600427

121. C. Chen, Y. Zhang, Y. Li, Y. Kuang, J. Song et al., Highly conductive, lightweight, low-tortuosity carbon frameworks as ultrathick 3D current collectors. Adv. Energy Mater. 7(17), 1700595 (2017). https://doi.org/10.1002/aenm.201700595

122. C.P. Yang, Y.X. Yin, S.F. Zhang, N.W. Li, Y.G. Guo, Accommodating lithium into 3D current collectors with a submicron skeleton towards long-life lithium metal anodes. Nat. Commun. 6, 8058 (2015). https://doi.org/10.1038/ncomms9058

123. S.S. Chi, Y. Liu, W.L. Song, L.Z. Fan, Q. Zhang, Prestoring lithium into stable 3D nickel foam host as dendrite-free lithium metal anode. Adv. Funct. Mater. 27(24), 1700348 (2017). https://doi.org/10.1002/adfm.201700348

124. H. Zhao, D. Lei, Y.B. He, Y. Yuan, Q. Yun et al., Compact 3D copper with uniform porous structure derived by electrochemical dealloying as dendrite-free lithium metal anode current collector. Adv. Energy Mater. 8(19), 1800266 (2018). https://doi.org/10.1002/aenm.201800266 